\title{
Modeling Changes in Mineral Assemblages and Sorptive Capacity Within the Altered Zone: Analytical Data for Flow-Through Experiment
}

\author{
L. DeLoach \\ J. Johnson \\ W. Glassley \\ K. Knauss
}

October 1997

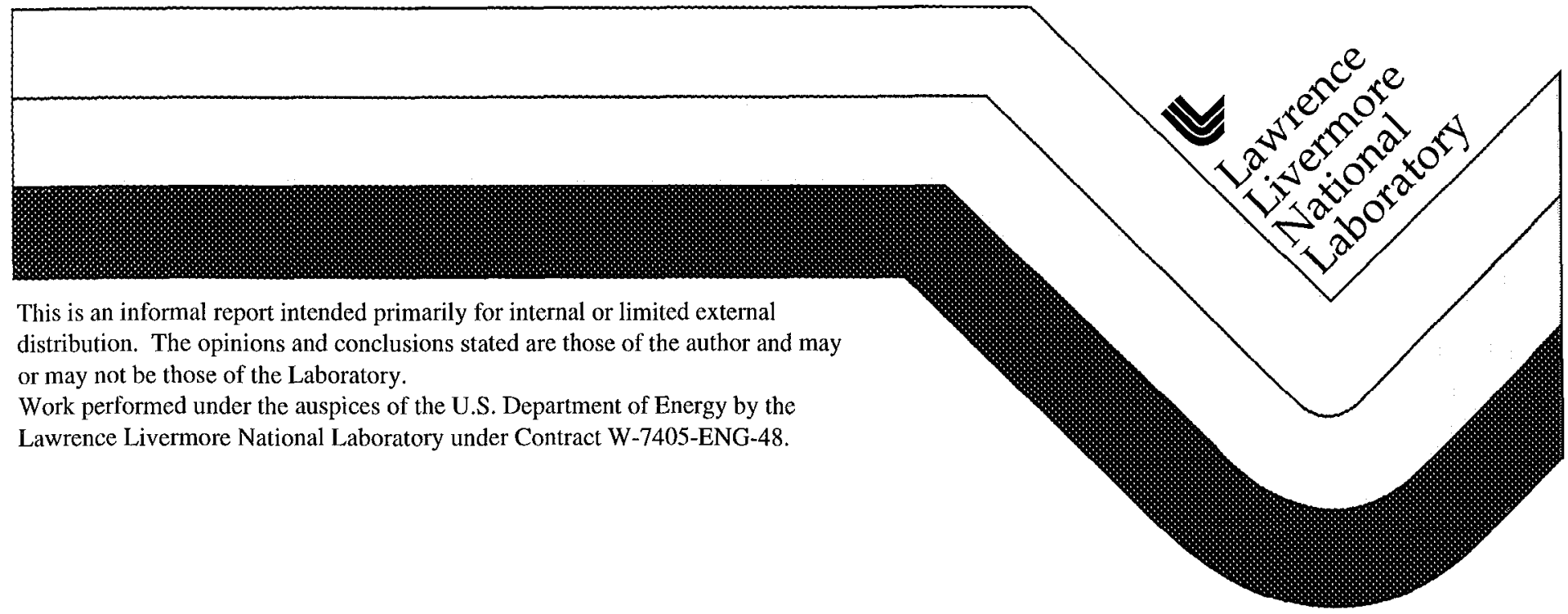




\section{DISCLAIMER}

This document was prepared as an account of work sponsored by an agency of the United States Government. Neither the United States Government nor the University of California nor any of their employees, makes any warranty, express or implied, or assumes any legal liability or responsibility for the accuracy, completeness, or usefulness of any information, apparatus, product, or process disclosed or represents that its use would not infringe privately owned rights. Reference herein to any specific commercial product, process, or service by trade name, trademark, manufacturer, or otherwise, does not necessarily constitute or imply its endorsement, recommendation, or favoring by the United States Government or the University of California. The views and opinions of authors expressed herein do not necessarily state or reflect those of the United States Government or the University of California, and shall not be used for advertising or product endorsement purposes.

This report has been reproduced directly from the best available copy.

Available to DOE and DOE contractors from the Office of Scientific and Technical Information

P.O Box 62, Oak Ridge, TN 37831

Prices available from (423) 576-8401

Available to the public from the

National Technical Information Service

U.S. Department of Commerce

5285 Port Royal Rd.

Springfield, VA 22161 


\title{
Modeling Changes in Mineral Assemblages and Sorptive Capacity within the Altered Zone: Analytical Data for Flow-Through Experiment
}

\author{
Laura DeLoach \\ Jim Johnson \\ William Glassley \\ Kevin Knauss
}

Lawrence Livermore National Laboratory

Livermore, CA 94550

Level 4 Milestone SPL1DM4

WBS 1.2.3.10.1

Summary Account TR3A1FB1 


\section{Contents}

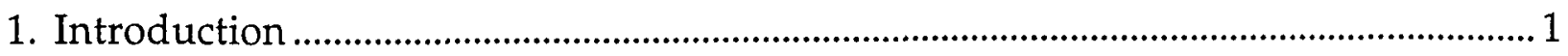

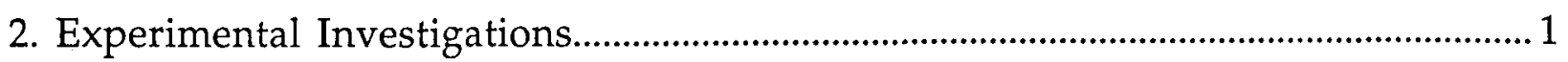

2.1 Starting Material Characterization and Preparation .............................................. 2

2.2 Experiment Design...................................................................................................

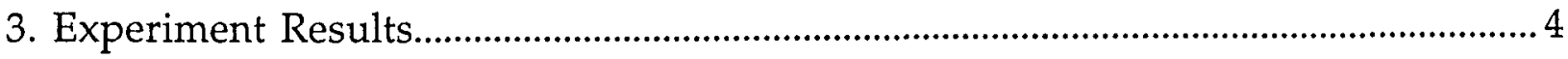

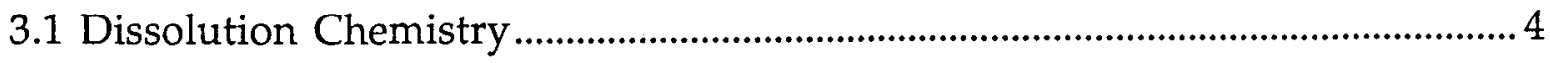

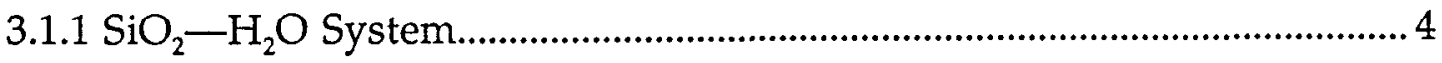

3.1.2 Topopah Spring Tuff (Si-Na-Al-K-Ca- $\left.\mathrm{H}_{2} \mathrm{O}\right)$............................................ 5

3.2 Postmortem Solid Characterization.................................................................... 6

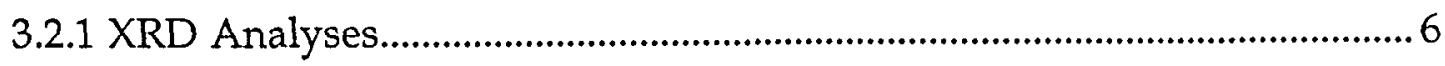

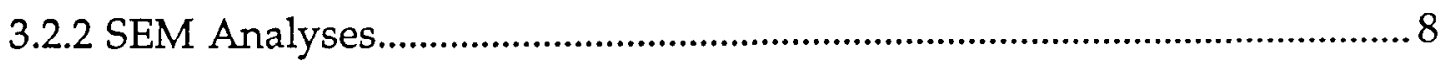

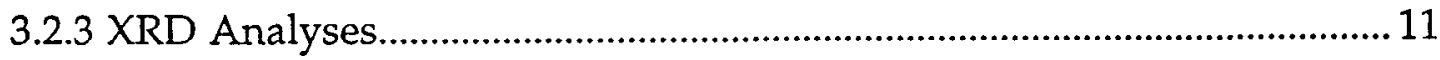

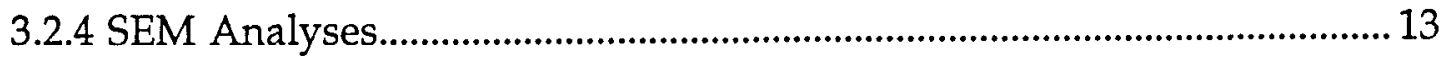

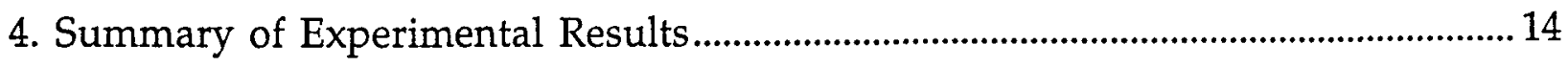

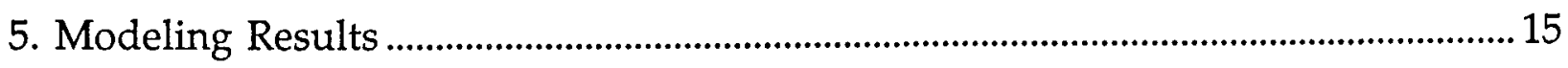

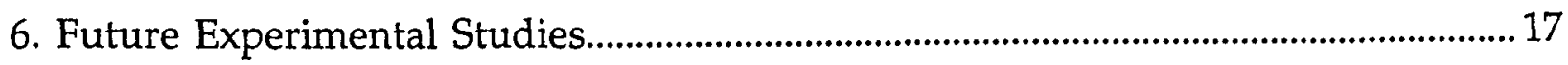

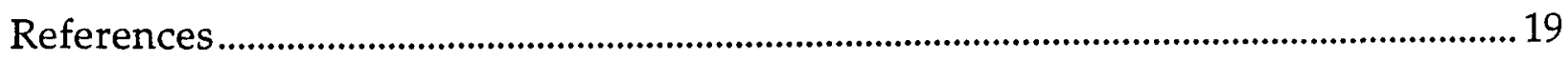

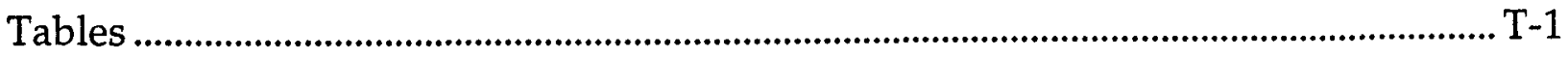

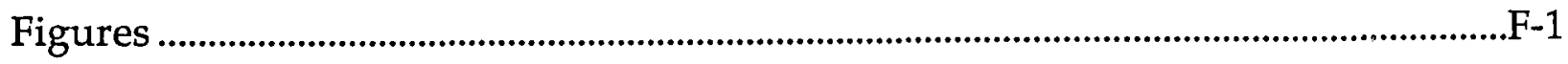




\section{Modeling Changes in Mineral Assemblages and Sorptive Capacity within the Altered Zone}

\section{Introduction}

Mineral changes that may occur within the altered zone (AZ) will develop in response to complex interactions among condensate, pore waters, fracture mineralogy, and the mineralogy of the in situ rocks. At the Yucca Mountain site, the mineralogy of the in situ rock varies from one lithologic unit to another, reflecting different initial bulk rock chemistries and different degrees of devitrification and welding. To account for these variations when describing the possible changes the potential repository block will experience during heating and fluid movement, a credible database of experimental results describing the chemical and mineralogical consequences of rock-water interaction must be available; against this, modeling capabilities are compared. Once the capability is established to accurately simulate the time-dependent evolution of rock-water systems at elevated temperatures, confidence can be placed in models of the mineral changes expected within the AZ.

This report describes experiments and modeling that consider the effects of different starting materials on mineral evolution and on the rates of mineral formation. Bounds are placed on the kinetics of the controlling dissolution-rate constants, which are the fundamental parameters that influence secondary mineral development. The sensitivity of the results to different secondary minerals is considered in the simulations. The most significant parameters affecting the results are shown to be the effective surface areas of the phases involved, the rate constants for the phases, and, for the case of vitric material, the model used for glass dissolution.

\section{Experimental Investigations}

A series of plug-flow-reactor (PFR) experiments was designed to effectively test the reactive transport model's ability to reproduce observed measured variables, such as water chemistry and secondary mineral production, under highly constrained conditions. Thus far, four experiments, with varied compositional complexity, have been completed, and the dissolution chemistries and mineral production have been recorded. The primary distinction among these four experiments was with respect to the solid forming the plug: in particular, the compositions and the surface areas of the selected materials varied among the four experiments. Specifically, two experiments used the monominerallic materials of amorphous silica and quartz, and two experiments used multiphase ash-flow tuff. In each, deionized water was forced through the plug of pulverized solid at temperatures and pressures held steady for a defined period of time. In addition to the fluid and rock compositions 
and the pressure-temperature conditions, the fluid flow rate, the size fraction of the crushed solid, the length of the solid plug formed, and the porosity of the plug were all well-constrained.

The fundamental data obtained from the individual experiments were the magnitudes of the steady-state effluent concentrations and the attainment time, both of which provided important constraints on subsequent reactive-transport simulations. Additionally, the post-mortem analyses of the individual plugs (compared to similar studies on prereacted material) led to qualitative assessment regarding dissolution and precipitation that are directly attributable to the specific fluid-rock interactions.

\subsection{Starting Material Characterization and Preparation}

Each of the two monominerallic experiments consisted of an $\mathrm{SiO}_{2}$ starting material. Experiment PFR2 used a large ingot of Supracil (from Heraeus Amersil, Inc.), a pure silica glass, which-from a structural and thermodynamic point of view-can be closely approximated as low $-\mathrm{H}_{2} \mathrm{O}$ amorphous silica. Experiment PFR3 used a quartz sample derived from a single crystal collected at Red Horse Lake in Lyndhurst, Ontario (a complete characterization and description are recorded by Knauss and Wolery [1988]).

The two multiphase materials used in subsequent experiments were compositionally equivalent, high-silica rhyolite tuffs. The starting material for PFR5 was a densely welded, completely devitrified tuff from the Topopah Spring Member of the Paintbrush Tuff (TSw2) of Yucca Mountain, Nevada. The bulk of the sample was the fine-grained devitrification products cristobalite, quartz, and alkali feldspar; phenocrysts were reported to make up less than $2 \%$ of the rock (Knauss et al., 1985; 1986). For PFR8, a densely welded vitric tuff was selected. It was the basal vitrophyre of the Topopah Spring tuff (TSw3) collected from the same general region. The vitric tuff is $70 \%$ to $80 \%$ high-silica $\left(74 \% \mathrm{SiO}_{2}\right)$ glass, with alkali feldspar, quartz, and biotite as primary minerals (Broxton et al., 1987; Vaniman et al., 1984). Basic descriptions of the starting materials are presented in Table 1.

For each of the PFR experiments, the solids were prepared and loaded to yield comparable size fraction and porosity among the different runs. For each, the solid was pulverized, then crushed further with a flat-plate grinder of tungsten carbide. These grains were sieved to achieve a uniform size fraction of $100 \pm 25 \mu \mathrm{m}$. (In the case of the devitrified tuff, the 100- $\mu \mathrm{m}$-sized particles were composed of multidomain regions on the order of 3-10 $\mu \mathrm{m}$ in size.) The samples were then repeatedly cleaned, with either isopropanol or deionized water, using an ultrasonic bath and gravitational settling to remove the bulk of fine, clay-sized particles adhering to the grain surfaces. A subsample of the washed material was separated out for representative surface area measurements.

To achieve a uniform porosity in the plug, the core holder was loaded with the uniformly sized grains and the contents were rinsed with deionized water to allow settling, refilled, and rinsed again as needed until a plug of material of the desired 
volume was achieved. Gravimetric determinations made of these loosely packed, uniformly sized grains gave an estimated porosity of $42.5 \%$. A slightly higher calculated porosity was also determined using the known weight of the grains, their approximate density, and the occupied volume.

The mineral-specific surface areas of the quartz and Supracil were measured using multipoint $\mathrm{Kr}$ gas adsorption Brunauer Emmett Teller (BET) analyses (Knauss and Copenhaver, 1995b). The bulk surface areas of the devitrified tuff and vitric tuff determined from a sample of the starting material were measured using multipoint $\mathrm{N}_{2}$ gas adsorption BET. All samples were baked at some elevated temperature before measuring. The results of the BET analyses are listed in Table 1. Generally, the regression analyses and associated error are quite good for the BET data; however, particularly in the case of the very small specific surface areas, the reproducibility is typically $10 \%$ to $20 \%$, which probably better reflects the measurement accuracy. A sample of Supracil was measured using both BET-Kr and BET- $\mathrm{N}_{2}$ for a comparison of the two methods; the difference is consistent with the reproducibility reported.

\subsection{Experiment Design}

The experimental flow-through system was designed for fluid-rock interaction studies at elevated temperatures and pressures. The actual PFR comprised a hightemperature three-zone furnace; a high-pressure, two-piston metering pump; an electronic controller; transducers above and below the sample column; and a gasbalanced, dome-type back-pressure regulator. A reservoir contained the reacting fluid that was meted out.

The core holder, a pure Ti-column, measured $0.66 \mathrm{~cm}$ inside diameter and $31 \mathrm{~cm}$ in length and provided a good physical model of idealized one-dimensional flow. In each run, the core holder was inserted into the furnace with the crushed material formed into a plug of solid. Deionized water served as the infiltrating fluid. The flow was at a steady rate of about $1 \mathrm{ml} / \mathrm{hr}$ throughout the course of the experiments. In most cases, elevated temperatures and pressures were established and stabilized within the first few hours of the start of each experiment. The actual experimental parameters of temperature, pressure, plug length, duration, and flow rate that defined the individual PFR experiments are summarized in Table 2.

Samples of the fluid exiting the reaction vessel through the back-pressure regulator were collected by means of a plastic syringe. Periodically, the fluid's chemistry was analyzed after filtration by means of a $0.2 \mu \mathrm{m}$ syringe tip filter. Liquid chromatography (LC) was employed for anion determination, and inductively coupled plasma and atomic emission spectrometry (ICP-AES) was used for cation analysis. This provided a characterization of the dissolution chemistry of the plug as well as a determination of the mass flow rate. Fluid samples were also obtained for the measurement of $\mathrm{pH}$ at room temperature. The actual solution chemistry as a function of time was used to constrain the reaction kinetics for appropriate phases 
in the computer modeling. The $\mathrm{pH}$ value and the solution composition considered together for charge balance were a starting point for subsequent calculation of the in situ $\mathrm{pH}$.

After cooling, the solids were taken from the reaction vessel, allowed to dry, and separated for qualitative solid-phase analysis to be determined as a function of sample location along the fluid flow path. Ideally, the sample plug was to be removed leaving the actual position within the core holder precisely preserved; in practice, only the relative positions of the sample within the column were satisfactorily maintained. Without destroying the core holder, the only adequate removal of the solid was accomplished by using a push rod to extrude the damp core. In this manner, the core was unavoidably compressed along its length. The approximate positions of each volume of solid separated for study were then estimated by measuring the dried weight of each subsample, assuming a bulk density and porosity, calculating the volume of the reactor tube occupied, and extrapolating its occupied length in the tube. As a result, reported positions for subsamples removed from the plugs were estimated within $\pm 2 \mathrm{~cm}$.

The solid-sample characterization was emphasized for the experimental investigations in which significant precipitation of secondary phases was anticipated. The characterization techniques that have been employed include $X$-ray diffraction (XRD), scanning electron microscopy (SEM) imaging, and $X$-ray spectroscopy.

\section{Experiment Results}

\subsection{Dissolution Chemistry}

Experiments PFR2 and PFR3 established experimentally the time to attain steadystate outlet concentration and magnitude for pure dissolution of an $\mathrm{SiO}_{2}$ phase under varied kinetic parameters. Experiments PFR5 and PFR8 were the multiphase systems, and the evolution of solution chemistry as a function of time were indicators for constraining the models of reaction kinetics for various mineral phases.

\subsection{1 $\mathrm{SiO}_{2}-\mathrm{H}_{2} \mathrm{O}$ System}

The amorphous silica (PFR2) and quartz (PFR3) experiments were included to establish whether the laboratory-measured dissolution kinetics of these materials were adequate, and whether the conceptualization of the reaction process was appropriate. The silica concentration (in ppm) was measured for collected fluid samples by ICP-AES; a plot of Si evolution is shown, for PFR2 and PFR3, in Figure 1. In both cases, the flow rate of $\sim 25 \mathrm{ml} /$ day and the short plug length of $3-5 \mathrm{~cm}$ (see Table 2) meant that a high fluid volume passed through the crushed plug by the 
time of the initial sampling (one "fluid volume" would be the total volume of liquid needed to fill the sample pore volume; thus, by definition, $\sim 37$ fluid volumes would have flowed through the quartz plug at first sampling).

As a consequence, the steady-state outlet $\mathrm{Si}$ concentrations were expected long before the first sample was taken. In the raw data shown in Figure 1, the Si concentrations for quartz were consistent with this expectation; however, the Supracil appeared to approach steady-state after three days. This contradictory behavior suggested sampling and/or analytical errors were incurred (based on thermodynamic and kinetic constraints).

The true steady-state outlet $\mathrm{Si}$ concentration for the amorphous silica was best represented by the average of the last four data points, $315 \mathrm{ppm}$. The Si concentration determined for the quartz run was $105 \mathrm{ppm}$, the average of the nine measurements taken. As expected, the greater surface area (Table 1) and dissolution rate of the amorphous silica (Rimstidt and Barnes, 1980) resulted in a larger steadystate outlet concentration than obtained for quartz. Post-mortem analysis of the solids in both cases revealed no secondary precipitation occurred, even though the Si concentration achieved for the Supracil represented supersaturation with respect to quartz (155.2 ppm Si) and cristobalite (291.9 ppm Si). The two steady-state Si values reported for the amorphous $\mathrm{SiO}_{2}$ and quartz were adopted for subsequent reactive-transport calculations.

\subsubsection{Topopah Spring Tuff (Si-Na-Al-K-Ca- $\mathrm{H}_{2} \mathrm{O}$ )}

In addition to there being a greater level of compositional complexity, experiment parameters were adjusted from those used in the first runs (Table 2). To ensure the achievement of steady-state outlet fluid chemistry, additional solid was used to lengthen the plug, and the experiment was conducted over a longer time period. The extended flow path was also expected to aid the potential precipitation of secondary hydrothermal phases.

The sampled fluid composition determined by ICP-AES and LC are plotted in Figures 2-4. The measured $\mathrm{pH}$ is plotted against time in Figure 5. The evolving cation chemistry-which included $\mathrm{Si}, \mathrm{Na}, \mathrm{Al}, \mathrm{K}$, and $\mathrm{Ca}-$ is graphed in Figure 2 for PFR5 (devitrified tuff) and in Figure 3 for PFR8 (vitric tuff). The lower concentration species of $\mathrm{Na}, \mathrm{Al}, \mathrm{K}$, and $\mathrm{Ca}$ in $\mathrm{ppm}$ are read from the $\mathrm{y}$-axis scale on the left-hand side. The higher concentration Si species is read using the y-axis scale on the righthand side. Figure 4 is a graph of the anion composition for the vitric tuff; no corresponding measurements were made for PFR5. The steady-state outlet concentrations observed in both experiments appear to be realized in about 4 days.

The steady-state outlet concentrations observed for PFR5 were based on the average concentration of the particular species from day 4 through day 40 (Figure 2). The steady-state values determined were $355 \mathrm{ppm} \mathrm{Si}, 15 \mathrm{ppm} \mathrm{Na}, 7.5 \mathrm{ppm} \mathrm{Al}, 2.5 \mathrm{ppm} \mathrm{K}$, and $0.008 \mathrm{ppm} \mathrm{Ca}$. Although $\mathrm{Mg}, \mathrm{Mn}$, and Fe were also sought analytically, their presence was not measurable, given the detection limits of the instrument. 
The steady-state outlet concentrations observed for PFR8 were the average of concentration measures reported for day 6 through day 42 (excluding the $\mathrm{Na}$ point outlier) (Figure 3). The approximate concentrations determined were $420 \mathrm{ppm} \mathrm{Si}, 49$ ppm Na, $22 \mathrm{ppm} \mathrm{Al}$, and $14 \mathrm{ppm} \mathrm{K}$. The presence of $\mathrm{Ca}$ and $\mathrm{Mg}$ was detected in trace amounts for only a few of the fluid samples tested. Figure 4 indicates that the anion chemistry rises rapidly and then appears to exhibit a slow, steady decrease with time. It should be noted that the first few data points on both the cation and anion chemistry graphs are possibly affected by dramatic temperature fluctuations that resulted when the furnace temperature initially overshot and then was corrected to the desired experimental settings.

The bulk composition, the size fraction, the infiltrating fluid, and the experiment parameters of the two runs with Topopah Spring tuff were virtually identical. The vitric tuff produced significantly higher magnitudes of the steady-state effluent concentrations than did the devitrified tuff, which is consistent with both the higher dissolution rates and the higher surfaces areas. The higher alkalinity was also reflected in steady-state $\mathrm{pH}$ values; the fluid from the vitric tuff had a $\mathrm{pH}$ of approximately 9.28, whereas the devitrified tuff had a $\mathrm{pH}$ of 8.48 .

\subsection{Postmortem Solid Characterization}

Although the two flow-through experiments using $\mathrm{SiO}_{2}$ did not produce any measurable quantities of secondary phases, experiments PFR5 and PFR8 were designed with the expectation of reaching and maintaining steady-state dissolution of primary phases while increasing the possibility of secondary-phase precipitation. To assess the extent to which solids had been changed through dissolution and precipitation, a study was made of the hydrothermally reacted material from each experiment, and results were compared with the starting material from the two runs.

\section{PFR5-Devitrified Tuff}

The starting material for PFR5 was analyzed by XRD and imaged with SEM to characterize the abundance and texture of the phases present. Similarly, the reacted material was separated out into subsamples, mapped according to the approximate distances from the fluid inlet end, and characterized using XRD and SEM. The subsamples were designated according to their identified positions within the reactor vessel and are referred to in subsequent text as PFR5-A through PFR5-Z.

\subsubsection{XRD Analyses}

\section{Techniques}

$X R D$ analyses were carried out on a Scintag PAD-V generator equipped with a $\mathrm{Cu}$ tube, a Sieffert goniometer, and a solid-state detector. The operating parameters were $45 \mathrm{kV}$ and $35 \mathrm{~mA}$. Collimation was provided by a $1^{\circ}$ divergence and $2^{\circ}$ scatter slit on 
the tube and a $0.3 \mathrm{~mm}$ scatter and $0.2 \mathrm{~mm}$ registration on the detector. Step scans of $0.02^{\circ} 2 \theta$ with $2 \mathrm{sec}$ dwell times were obtained over the range $2-52^{\circ} 2 \theta$. Mixtures of the ground specimen and a corundum standard were packed into side-mount holders of either stainless steel or Lucite.

To quantify the $X$-ray diffraction data, a corundum standard was added to each subsample of the core in a mass ratio of approximately 1:4. The diffraction intensities from the components of the sample were then referenced to the strongest diffraction line of corundum. The procedure used reference intensity ratios (RIRs) previously determined for this instrument (Roberts and Viani, 1997b) for each component of the rock from a 1:1 mixture by weight of the individual phase and corundum. (An RIR is the ratio of the integrated intensity of the mineral's reference peak to the integrated intensity of the $43.3^{\circ} 2 \theta$ corundum peak.) Intensities for the selected diffraction pattern peaks were integrated, and profile-fitting of overlapped peaks were constructed using the software package WinJade (Winjade 3.0, for Windows, Materials Data, Inc., Livermore, CA). The fractional abundance of the component mineral phases was then calculated using the integrated intensities according to formalisms described by Chung (1974). Because determinations of any given phase were not dependent on the relative abundance of the other phases present, the total percentages of the phases determined were not constrained to sum $100 \%$. Deviations from $100 \%$ in the summed totals, accordingly, suggest possible errors, as discussed in the text to follow. The estimated mineral abundance of the phases quartz, cristobalite, sodium feldspar, and potassium feldspar were determined using this technique. The observation of weak, low $2 \theta$ angle peaks in the scans suggested a mica or clay phase was also present as a trace mineral.

\section{Results}

The data are plotted in Figure 6 as "Abundance of mineral phases (\%)" versus "Approximate distance from fluid inlet $(\mathrm{cm})$." For comparison, XRD data for the pretreated rock are shown plotted arbitrarily at position "-2.5 cm" from the fluid inlet. Generally, multiple determinations (2-3) of repacked grain mounts for a given sample were reproducible within $\pm 10 \%$ for the silica polymorph phases, but the feldspars showed greater variation $( \pm 20 \%)$. In every case, summed totals for the samples yielded values greater than $100 \%$, which suggested a systematic overestimation of one or more of the phases present. In preparing the powdered mixture and the XRD mount, the procedures followed were according to accepted practices (Roberts and Viani, 1997a); therefore, any trends in the relative changes of a given phase among the samples were interpreted as real, with possible exceptions noted in the discussion.

The results indicated that cristobalite decreased in abundance within a few $\mathrm{cm}$ of the inlet by about 11 to 13 mass percent, absolute, relative to the starting material (simulations report volume percent changes; so, for comparison, a $13 \%$ volume change in cristobalite would correspond approximately to a $12 \%$ mass change). The feldspar abundances showed significant scatter, and their associated uncertainty $( \pm 20 \%)$ made it impossible to quantitatively determine the extent to which albite 
dissolution had occurred. Clearly, however, there was no location along the flow path where albite was completely removed. Finally, no detectable change was observed in the abundance of other mineral phases considered.

\section{Discussion}

The silica phases are represented in the two lower trends of Figure 6. The proportion of quartz in the rock, both before treatment and during the course of the PFR experiment, appeared to remain constant at an estimated $20 \%$ by mass. Neither dissolution nor precipitation of quartz during the experiment was indicated.

Cristobalite, on the other hand, in the pretreated rock was estimated to be present at $16 \%$, but the XRD results suggested the percentage of cristobalite in rock taken from the fluid inlet end of the experiment has dropped to $3 \%$ to $5 \%$. With increasing distance from the fluid inlet, the cristobalite increased in proportion and reached original pretreated rock abundance at approximately $20 \mathrm{~cm}$ from the inlet. It is noteworthy that the last data point in Figure 6 does not follow this trend. However, $X R D$ data for the other phases in the last sample collected near the outlet also displayed anomalous trends, which makes the information difficult to interpret. Whether this reflects mineralogical heterogeneity in the original sample or the consequences of processes during reaction in the PFR remains to be established. Clearly, however, the source of Si dissolved into the PFR5 flow-through fluid was cristobalite, and significant precipitation of silica polymorphs was not confirmed by XRD.

The feldspar data exhibited no well-defined trends. This may reflect the fact that quantification by XRD is inherently more difficult for feldspars. Compositional variation directly affects the choice of the previously mentioned RIRs that have been derived for the calculations and, without an exact compositional match, error will be introduced. Also, orientation preferences contribute to relative peak height differences.

It was also noted during this investigation that diffraction intensities of the feldspar peaks were particularly sensitive to the particle sizes of the ground mixtures. The procedures for grinding powders included use of a Fritsch vibratory micro-mill for 40 minutes on an intermittent power cycle, a practice that has been used successfully in this laboratory to achieve particles sizes of $10 \mu \mathrm{m}$ or less. In this study, the powders appeared to clump together after about 25-30 min, rendering the remaining time essentially ineffective in reducing grain size. This was especially problematic when subsamples weighed much less than $1 \mathrm{~g}$. Finally, the original heterogeneous distribution of feldspar phenocrysts would further contribute to scatter in the feldspar abundance trends. Given these considerations, it was evident that the XRD data alone were insufficient to establish the dissolution and precipitation processes. 


\subsubsection{SEM Analyses}

\section{Techniques}

SEM imaging was used to examine the different subsamples collected from PFR5 along with the starting material. All samples were prepared by either $\mathrm{C}$ - or Ptcoating the grain mount to ameliorate charge buildup from the electron beam. Studies were then conducted using one of two SEM instruments: a Hitachi S- 4500 using accelerating voltages down to $2 \mathrm{kV}$, and the Hitachi S-800 with X-ray spectroscopy capability and employing accelerating voltages down to $5 \mathrm{kV}$. Although imaging has been quite useful for visually identifying dissolution textures in these samples, phase identification using the $X$-ray spectra of phases less than $10 \mu \mathrm{m}$ in size was only qualitative because the accelerating voltages used for analysis $(\sim 10-15$ $\mathrm{kV})$ produce an $\mathrm{X}$-ray signal from a penetration depth of a few microns in silicatesmore than the dimensions of some phases observed. As a consequence, identification was made, where possible, by a combination of crystal morphology and semiquantitative analysis of the $\mathrm{X}$-ray spectra.

\section{Results and Discussion}

SEM observation of the unreacted crushed rock, sample PFR5-Z, revealed that finegrained, intergrown alkali feldspar and silica polymorphs dominated the mineralogy. Figure 7a is an SEM photograph of a well-developed relict-grain of alkali feldspar and intimately intergrown regions of cristobalite or quartz. The $X$-ray spectrum in Figure $7 \mathrm{~b}$, which is of the generally corresponding region, reflects the constituent elements $\mathrm{K}, \mathrm{Al}, \mathrm{Na}$, and $\mathrm{Si}$, with a particularly strong $\mathrm{Si}$ peak that would be consistent with this identification. The very prominent feldspar cleavages were observed throughout. A magnified photograph imaged on the rough, outer surface is shown in Figure 8. The fine-grained nature of the silica phase is evident (the feldspar is barely visible in the lower right-hand corner of the photo). Figure 9 is an SEM photograph of a grain of biotite intergrown with feldspar. These SEM photographs are characteristic of the features observed throughout the grain mount of the unreacted rock. The observations can be summarized as grains composed of well-developed crystalline phases including feldspar, quartz, and biotite in a finegrained silica matrix, which probably consists of quartz, cristobalite, and some alkali feldspar.

A grain mount prepared from the subsample removed closest to the fluid inlet (sample PFR5-A) showed very different textural features when compared with the unreacted rock (sample PFR5-Z). Sample PFR5-A exhibited dissolution textures throughout. Figure 10 is an SEM photograph of a grain where the feldspar cleavage faces are still in evidence, but cleavage faces lack the smooth surfaces, and the grain appears to have been etched along the cleavage planes. Gaping holes give the appearance of material (probably the cristobalite) being more completely dissolved away. The photograph in Figure 11a is a higher magnification of a K-rich alkali feldspar and more clearly reveals the strong dissolution along intersecting planes 
producing chevron-like projections; the corresponding $X$-ray spectrum displayed in Figure $11 \mathrm{~b}$ is consistent with this identification.

The presence of a bladelike mineral, typically $1-2 \mu \mathrm{m}$ in length, was repeatedly observed among the subsamples of the hydrothermally treated rock. Figure 12 is an SEM photograph of this phase in its usual occurrence: lying on the surface of a region exhibiting strong dissolution. $X$-ray spectra of a region, which included one of these blades and an immediately adjacent region, revealed $\mathrm{Fe}$ to be uniquely present where the blades were observed. Although their presence was not noticed in the pretreated rock, the blades were most probably remnant hematite exposed on surfaces after the fine-grained matrix was leached from around them. Hematite was abundant as a trace mineral in this rock and thus was not considered to be a run product (for further description of the occurrence of this phase, see Glassley and Boyd [1995]).

The subsample collected closest to the fluid outlet, PFR5-M, is distinct from the sample closest to the inlet end. Dissolution textures were clearly present, but the degree to which they were developed was less. Figure 13 is an SEM photograph of a typical feldspar. The surfaces all have an etched or frosted appearance as a result of the incipient dissolution, and the edges and faces are rounded and worn (cf. Figure $7 \mathrm{a}$ ). Evidence of preferential dissolution is observed in what appears to be a perthitic feldspar shown in the SEM photograph of Figure 14. Cleavage traces in the host and contact boundaries between exsolved phases are enhanced by dissolution. Figure 15a is the SEM photograph of, presumably, a twinned plagioclase, identified by the morphology and semiquantitative chemical analyses exhibited in the $X$-ray spectrum of Figure 15b (X-ray spectral analyses of both the "smooth" and more "etched" areas are similar). It appears that preferential dissolution has occurred between the twinned regions.

Run products from the PFR experiment were not in clear evidence, with one exception. In sample PFR5-M, spheres of silica (determined by X-ray spectroscopy) were observed (Figure 16a and 16b). Individual phases were on the order of 10-30 $\mu \mathrm{m}$ in diameter and were previously observed in similar studies of hydrothermal interaction of Topopah Spring tuff (Knauss et al., 1985). The only other phase identified potentially as a run product or a product of quench was also found in the outlet sample. A phase with poor crystalline morphology has been observed on the surface of other minerals. Figure 17 is an SEM photograph of these; the morphology is similar to the claylike phases identified in the same Knauss study. Unfortunately, these grains are usually less than a micron in size, thus eliminating the possibility of $X$-ray spectral analysis.

SEM sample mounts prepared from intermediate subsamples to PFR5-A and PFR5$M$ exhibit different degrees of dissolution, but no significantly different features. Taken as a whole, the suite of subsamples collected from the PFR5 hydrothermal study of the devitrified tuff and observed using SEM techniques revealed a gradational dissolution pattern and correspondingly increased bulk porosity when compared with the starting material. Greatest porosity increase due to dissolution was unarguably at the inlet end of the flow path. The dissolution of the fine-grained 
matrix along the flow path was consistent with the dissolution of cristobalite indicated by the XRD findings. The abundant evidence of feldspar dissolution would explain the presence of $\mathrm{Na}, \mathrm{Al}, \mathrm{K}$, and $\mathrm{Ca}$ in the flow-through fluid. Evidence of alteration minerals along the flow path was not significant. A silica polymorph was identified as a secondary phase in the outlet sample, and a clay phase observed in the same outlet subsample was possibly a quench or run product.

\section{PFR8-Vitric Tuff}

The effort to remove the run-product solids from PFR8 led to an uncertainty in identifying the actual sample location within the core holder that was greater than that encountered with the PFR5 experiment. Although the relative position within the core was preserved for much of the reacted sample extruded, information about the location along the length of the plug was lost because the initial extrusion of sample with the push rod left approximately half of the mass lodged between the rod and the vessel walls. The effort to reclaim the sample left inside the tube produced a subsample that was undifferentiated with respect to location. Thus, four subsamples were separated out as representing the graduated positions along the fluid flow path from fluid inlet to fluid outlet; these have been designated as PFR8A through PFR8-D, respectively. One subsample, PFR8-U, was designated for the undifferentiated mass. Finally, one carefully retrieved sample from the walls of the vessel nearest the fluid inlet end was observed to have a high concentration of material with contrasting (light) color and was given the designation PFR8-UA.

Comparisons of the hydrothermally reacted samples and the unreacted starting material (PFR8-Z) were made using the XRD and SEM analytical tools. The characterization procedures followed were essentially the same, with minor exceptions, as those employed for PFR5. Additionally, bulk BET- $\mathrm{N}_{2}$ analyses were performed on the reacted sample PFR8-U. The increased surface area was approximately 6 times greater than for PFR8-Z (cf. Table 1), having an average measured value of $3.43 \mathrm{~m}^{2} / \mathrm{g}$.

\subsubsection{XRD Analyses}

\section{Techniques}

The XRD instrument and procedures for preparing the PFR8 samples were the same as those described in previous text for PFR5. One exception, however, was that a longer step scan of $2-72^{\circ} 2 \theta$ was collected and quantitative analysis was made using the software package SIRIQUANT (SIRIQUANT 2.0 for Windows, Sietronics, Australia), which used a Rietveld-type analysis. Rather than supplying the RIRs as required with the Chung method, this program fit the entire powder pattern using a least-squares refinement of the best fit between the observed XRD pattern and the calculated theoretical pattern, based on existing knowledge of the phases present and their structural properties. Because of the significant amorphous content, the samples were spiked with a known amount of corundum as before, but the weight 
percentage was provided as an input parameter. Visual matching of the calculated pattern and the observed ensured that all phases were considered. (This particular laboratory capability was added since the characterization of samples from PFR5.)

\section{Results and Discussion}

Unlike experiment PFR5, in which the crystalline phases of the devitrified tuff were the major components, in experiment PFR8, a silica-rich glass was the dominant component of the starting material. Minor crystalline phases that were measurable included cristobalite, alkali feldspar, and quartz; trace quantities of biotite, unspecified clay minerals and $\mathrm{Fe} / \mathrm{Ti}$ oxides were indicated. From the unreacted sample PFR8-Z, the component phases were determined to be present in the following quantities: glass $87 \%$, cristobalite $6 \%$, albite $6 \%$, and quartz $1 \%$. Contrary to employment of the Chung method for estimates of phases in PFR5, the sums of the relative abundance of phases in PFR8 were constrained to total 100\%; the total amorphous component was actually deduced by difference of the summed crystalline phases. This would be a known source of some error because, as discussed in subsequent text, minor phases identified by SEM were present. Furthermore, the quantification of phases when glass is present is complicated by errors associated with background subtraction. Further evaluation of samples by XRD may be undertaken to refine these results.

The reacted material collected from experiment PFR8 was divided into larger subsamples to increase the sample mass and thereby minimize the grinding problems previously observed. Four samples were collected representing the continuously changing position along the flow path, but XRD spectra revealed only minor differences. The amorphous scattering hump present in the starting sample's spectrum continued to have a dominant presence in the X-ray pattern of each of the reacted materials. In fact, the spectra were all very similar, except that quartz was completely eliminated in the two samples closest to the inlet. Nevertheless, some trends were demonstrated in the changes in phase abundance based on the SIRIQUANT findings; the changes, however, were small and might well be considered to be within the expected error bars. What is evident is that silica glass is the primary source of dissolution and for precipitation of secondary phases. The amorphous phase was present in the reacted samples in reduced abundance and determined to be between $86 \%$ and $81 \%$.

In the SEM studies (to follow), a significant increase of clays was observed as a result of the hydrothermal alteration of the tuff. The routine XRD scans, however, gave rise to only poorly defined peak in the low-angle $2 \theta$ region. Therefore, standard practices among clay mineralogists (e.g., Brown and Brindley [1980])) were employed to isolate the fine clay fractions of the reacted materials.

To separate out the clay phases, approximately $1 \mathrm{gm}$ of solid was taken from the reacted sample's undifferentiated material PFR8-U, with no standard added and no sample grinding. Deionized water was added, and the sample was dispersed using a high-power ultrasonic probe that has been demonstrated to be particularly useful in suspending clays. Following dispersion of the sample, the $<2-\mu \mathrm{m}$-sized fraction was 
obtained under centrifugal acceleration. The clay suspension was collected in a syringe, ejected onto a quartz slide, and left to air dry-a process which favors highly oriented specimens. A second sample was similarly prepared from the starting material PFR8-Z.

Low-angle $\left(2-20^{\circ} 2 \theta\right)$ XRD spectra were collected of the isolated fractions of clay-sized particles prepared from both the undifferentiated PFR8 material and the starting sample. The differences in the two spectra were significant: The spectrum of sample PFR8-U exhibited a readily identifiable clinoptilolite peak and another complex peak that could not be conclusively identified. On the other hand, sample PFR8-Z produced a spectrum with no observable peaks in the $2-20^{\circ} 2 \theta$ region. The results were thus consistent with the formation of new phases during the hydrothermal experiment.

To identify and test for the possibility of smectite and mixed-layer clays (i.e., clays that have some component of layers that swell), the PFR8-U sample was X-rayed again after allowing the sample to equilibrate for several days in an atmosphere of ethylene glycol. This time, when the low-angle region of the spectrum was scanned, two distinct peaks were identifiable where previously there had been one. From this test, it was concluded that illite was present in the reacted sample and was reflected in the XRD spectrum as a nonexpansible clay (i.e., a portion of the composite peak that did not shift). Also, smectite was present and represented by a clay peak that shifted to appropriately lower $2 \theta$ angles (larger d-spacings) with the glycol treatment. Although this study led to confident identification of the phases, the quantitative compositional analyses of these secondary minerals was unattainable.

\subsubsection{SEM Analyses}

\section{Results and Discussion}

The SEM imaging and X-ray studies of PFR8 were performed using the same instrumentation and settings as used for PFR5. SEM studies of the unreacted vitrophyre, PFR8-Z, revealed mostly angular, smooth-surfaced glassy grains. Figure 18 is a typical SEM photograph of these observations. A qualitative glass analysis is represented in Figure $18 \mathrm{~b}$. The $\mathrm{X}$-ray spectrum includes the major elements $\mathrm{Si}, \mathrm{Al}$, $\mathrm{K}, \mathrm{Na}$, and less Fe. $\mathrm{Mg}$ and $\mathrm{Ca}$ have also been observed. Regions of glass dissolution with minor clay alteration were also in evidence in the starting material, although the volume of alteration present was slight. Such a texture is exhibited in the photograph shown in Figure 19; the scalloping of the glass surface is roughened by dissolution and the comflake-like morphology is readily attributable to clays (see, for example, Welton [1984]). Here, the very thin nature of the clay flakes and poor surface coverage make the actual clay identification by X-ray spectroscopy highly improbable. The minor phases observed include biotite and alkali feldspar.

Comparatively, the SEM examination of grain mounts prepared from the reacted samples of PFR8 revealed that hydrothermal alteration of the vitrophyre at $250^{\circ} \mathrm{C}$ resulted in extensive glass dissolution and clay formation. The SEM photograph in Figure 20 shows characteristic claylike morphologies and is typical of grains found 
throughout the core (the sample is PFR8-A, subsample removed closest to fluid inlet end). This pattern of growth is sometimes referred to as honeycomb texture but is not uniquely attributable to a particular clay phase. In general, morphology alone is not adequate to identify the clay mineral present. The magnified view of another clay-rich region in Figure 21a was observed in sample PFR8-UA; it has an approximately corresponding $X$-ray spectrum (Figure $21 \mathrm{~b}$ ) that is consistent with the chemistry of an illite clay. The presence of illite had previously been demonstrated by XRD. The ribbons of clay seen in the SEM photograph in Figure 22 may be another morphological occurrence of illite, although, in this case, no associated chemistry can confirm the identification. Based on the XRD confirmation of smectite in the reacted sample, an effort was made to observe any visible distinctiveness among the clay-rich regions that might yield correspondingly unique $X$-ray spectra. At least in principle, a lower Al:Si ratio, and an insignificant presence of $\mathrm{K}$, might be consistent with the chemistry expected for an isolated smectite phase.

Although clays appear to be the dominant secondary phase produced during the PFR8 experiment, clusters of blocky crystals were observed among some very clayrich particles. The sample PFR8-UA, carefully removed from the walls of the reaction tube at the vessel's inlet end, initially appeared to be composed entirely of densely agglomerated clays, as seen in Figure 23. Closer examination, however, revealed the presence of prismatic crystals a few microns in length. The SEM photograph in Figure 24a reveals a very sizable cluster of these crystals, and Figure $24 \mathrm{~b}$, the corresponding $X$-ray spectrum, is consistent with the zeolite clinoptilolite previously identified in the XRD analyses. Not surprisingly, the X-ray spectral analysis reveals a Ca-rich phase, which is consistent with the high- $\mathrm{Na}$, low-Ca content of the dissolution chemistry reported previously. The finding of clinoptilolite correlates well to a hydrothermal study of glassy Topopah Spring tuff previously described by Knauss (1987).

SEM results of samples taken from PFR8 demonstrate strong glass dissolution textures and abundant secondary mineral precipitation including clays and zeolite. The presence of clays is ubiquitous along the flow path; the zeolite clinoptilolite is significant near the fluid inlet of the reactor vessel.

\section{Summary of Experimental Results}

The PFR studies reported herein compared the observed hydrothermal reactions resulting from starting materials of varying composition and surface area. Four different starting materials were reacted with deionized water at $250^{\circ} \mathrm{C}$. The important $\mathrm{SiO}_{2}$ system was represented by quartz and amorphous silica, and comparison of the experimental measurements and the simulated results were needed to verify the reactive-transport code prior to pursuing more complex systems. The critical repository-relevant units at Yucca Mountain, Nevada, which include both the Topopah Spring devitrified unit and the underlying basal vitrophyre, were subsequently studied. The important observations that were recorded can be summarized: 
The dissolution of crushed silica and rhyolitic tuff at elevated

temperatures $\left(240^{\circ}-250^{\circ} \mathrm{C}\right)$ rapidly generated a steady-state of ions in solution.

Steady-state Si concentration for the quartz plug was observed within hours of temperature stabilization $\left(\sim 240^{\circ} \mathrm{C}\right)$ and was determined to be $105 \mathrm{ppm}$. The amorphous silica plug experiment having a higher surface area and dissolution rate approached a steady-state concentration of $315 \mathrm{ppm}$, indicating supersaturation with respect to quartz (155.2 ppm Si) and also cristobalite (291.9 ppm Si).

The steady-state outlet concentrations of the dissolving Topopah Spring devitrified tuff occurred within the first 4 days of stable heating $\left(\sim 240^{\circ} \mathrm{C}\right)$ and were $355 \mathrm{ppm} \mathrm{Si}$, $15 \mathrm{ppm} \mathrm{Na}, 7.5 \mathrm{ppm} \mathrm{Al}, 2.5 \mathrm{ppm} \mathrm{K}$, and $0.008 \mathrm{ppm} \mathrm{Ca}$. The dissolution of the basal vitrophyre of the Topopah Spring tuff gave rise within the first 4 days to steady-state outlet concentrations (at $250^{\circ} \mathrm{C}$ ) determined to be $420 \mathrm{ppm} \mathrm{Si}, 49 \mathrm{ppm} \mathrm{Na}, 22 \mathrm{ppm} \mathrm{Al}$, and $14 \mathrm{ppm} \mathrm{K}$.

Post-mortem analyses of the multiphase tuff revealed that dissolution was greatest at the inlet of the fluid flow path for both the devitrified sample and the vitrophyre and that secondary precipitation on the timescale of study ( 42 days) was significant only in the vitric tuff.

XRD studies of samples collected along the flow path of the devitrified tuff experiment revealed that cristobalite was preferentially dissolved and decreasingly depleted from the fluid inlet to the fluid outlet. The SEM imaging verified that feldspars followed a similar pattern of dissolution with more complete dissolution nearest the fluid inlet. The resulting dissolution texture demonstrated increases, for certain minerals, in bulk porosity and specific surface area. With one exception (an $\mathrm{SiO}_{2}$ polymorph), no significant precipitation of phases was observed.

Observations of the reacted vitrophyre made using $\mathrm{XRD}$, revealed silica glass was the principal source of the dissolution chemistry and the precipitation of phases. Identification of the secondary phases was made by XRD and revealed that illite, smectite, and clinoptilolite were formed. A comparison, made with SEM imaging, of the unreacted and reacted vitrophyre demonstrated the extensive dissolution and precipitation processes that occurred along the flow path.

\section{Modeling Results}

The evolution of effluent fluid concentrations measured in PFR experiments PFR2, PFR3, PFR5, and PFR8 can be modeled using the reactive-transport simulator OS3D/GIMRT (Steefel and Yabusaki, 1996). Accurate representation of this evolution requires the following 
- Precise specification of the experimental system (Tables 1-2):

- Geometry

- P-T conditions

- Flow rate

- Porosity

- Grain size

- Specific surface area

- Sufficiently complete and accurate compositional, thermodynamic, and kinetic data for the infiltrating fluid and crushed material

In the case of PFR2 (Supracil ${ }^{1}$ ), PFR3 (quartz), and PFR5 (rhyolitic tuff), these data are readily available; our modeling efforts have clearly demonstrated the ability of OS3D/GIMRT to accurately simulate observed effluent concentrations and to corroborate functional relationships between mineral dissolution rates and specific surface area (Johnson et al., 1997a; 1997b). In contrast, reactive transport simulation of PFR8 (vitric tuff) requires a priori (and largely empirical) estimation of thermodynamic and kinetic data for a fictive glass phase, which dominates the vitrophyre mineralogy. As a result, the PFR8 modeling efforts are necessarily more poorly constrained than are the analogous PFR2, 3, and 5 simulations. Nevertheless, preliminary models do provide relatively close approximation to PFR8 observations. This section provides descriptions of the vitric tuff mineralogy, the procedure for estimating requisite thermodynamic and kinetic properties of the fictive glass phase, the initial model results, and future directions for honing these calculations.

The actual and model vitrophyre mineralogy is summarized in Table 3. As shown in this table, observed phenocryst compositions have been resolved to their endmember components in the model, and the vitric matrix is represented as a fictive eight-oxygen glass species (containing $\mathrm{K}, \mathrm{Na}, \mathrm{Si}, \mathrm{Al}, \mathrm{Fe}$, and $\mathrm{Mg}$ ), whose composition is consistent with microprobe analyses of the basal vitrophyre. The equilibrium constant for hydrolysis of this glass is constrained to replicate the experimentally observed dissolution of this material. The kinetic data used in PFR8 simulations are given in Table 4. Excepting the glass dissolution-rate constant, most of these data are relatively well known. Although there is experimental evidence that the dissolution rate of albite-composition glass is 10-100 times faster than that of crystalline albite (Bourcier, 1997), the modeling results (see subsequent information) suggest that the PFR8 glass matrix (which is essentially an K-feldspar-albite glass) does not dissolve more rapidly than do either crystalline $\mathrm{K}$-feldspar or albite. In fact, the results indicate that the appropriate dissolution rate for this glass may be approximately that for $\mathrm{K}$-feldspar, which rate is two orders of magnitude slower than that of albite.

\footnotetext{
' Supracil is a very pure, low-water silica glass that, from a structural and thermodynamic standpoint, can be approximated as amorphous silica.
} 
Preliminary PFR8 modeling results are provided in Table 5, which compares observed effluent concentrations with their model analogs for a sequence of simulations. In simulation $A$, precipitation of secondary phases is not artificially suppressed, and the relative magnitudes of $\mathrm{Si}, \mathrm{Na}, \mathrm{Al}, \mathrm{K}$, and $\mathrm{Ca}$ concentration are correctly predicted by the model; however, the absolute magnitudes of simulated concentrations are significantly low. Excepting $\mathrm{K}$ and $\mathrm{Ca}$, these model effluent concentrations can be increased to fairly close agreement with their experimental values by suppressing secondary precipitation of albite and the silica polymorphs (simulation B); this is supported by PFR8 observations. Suppression of secondary Kfeldspar precipitation, which will increase $\mathrm{K}$ concentration and is also supported by experiment, increases this concentration far too much (simulation D). Suppression of other K-bearing secondary phases does not have a significant effect on raising effluent $\mathrm{K}$ concentration (simulations $\mathrm{E}-\mathrm{F}$ ). Note that all of these simulations do predict volumetrically trace precipitation of secondary illite, smectite, and clinoptilolite, in agreement with post-mortem PFR8 observations.

The relatively close match between observed effluent concentrations and those predicted in simulations B and E-F suggest that the reactive transport model provides a reasonably good representation of vitric tuff dissolution. However, the discrepancy between experimental and simulated $\mathrm{K}$ and $\mathrm{Ca}$ concentrations remains unresolved. Several obvious avenues towards improving the simulations are currently being pursued; most important of these are incorporation of (1) a more rigorous thermodynamic and kinetic representation of the fictive glass phase and (2) explicit provision for the thermodynamic and kinetic effects of solid solution.

\section{Future Experimental Studies}

The hydrothermal studies that have just been completed and described for the Topopah Springs devitrified tuff (repository-equivalent rock) and the for the vitric tuff (basal vitrophyre) contribute to our basic understanding of mineralogy and water chemistry evolution at Yucca Mountain. In particular, the variation in steadystate effluent concentrations, their attainment time, and the precipitation of secondary phases that were observed to occur at $250^{\circ} \mathrm{C}$ make up the record of physical evidence being developed and employed in modeling the reactive transport processes. We would like to further establish lower temperature effects on the behavior recorded, using the PFR for additional studies with the most rapid dissolving tuff. Finally, a comparative study of the repository-relevant Topopah Spring upper vitrophyre (unit Ptn) is also to be conducted.

Incorporated into these upcoming studies are improvements that will address certain difficulties that contributed to information loss (regarding subsamples and their respective positions along the flow path). As noted, upon completing the experiments reported, the solid plug of material was extruded from the Ti core holder with the aid of a push rod. This resulted in two unfortunate events: 1) sample that immediately dislodged was compressed along its length so that, although the relative position was preserved, some method of estimating its actual location inside the core was required, and 2) some portion of the solid remained 
lodged between the push rod and reactor vessel walls and was therefore not readily removed without loss of most of its position information.

Efforts have been focused on the development of a nonreusable liner designed to be fully removed from the reactor vessel with solid sample fully intact. Samples will then be retrievable by one of two methods: A lengthwise cut down the liner will enable it to be opened out flat, and the actual sample position may then be precisely recorded; alternatively (or additionally), cross sections may be cut through the tube at regular intervals, impregnated with epoxy, and polished so that intergrain textures are preserved for study and flow-path position is accurately known. The significance of the first appearance of secondary phases and the quantification of dissolution changes with respect to precise position along the flow path will further aid the refinements for simulations projecting repository performance. 


\section{References}

Blum, A.E., and L.L. Stillings (1995). "Feldspar dissolution kinetics." A.F. White and S. L. Brantley (eds). Chemical weathering rates of silicate minerals. Washington, DC: Min. Soc. Amer. 31:291-351.

Bourcier, W.L. (1997). Lawrence Livermore National Laboratory: personal conversation, August 27, 1997.

Brown, G., and G.W. Brindley (eds). (1980). "X-ray diffraction procedures for clay mineral identification." Crystal Structures of Clay Minerals and their Xray Identification. London: Mineralogical Society.

Broxton, D.E., D.L. Bish, and R.G. Warren (1987). "Distribution and Chemistry of Diagentic Minerals at Yucca Mountain, Nye County, Nevada." Clays and Clay Minerals 35(2):89-110.

Chung, F.H. (1974). “Quantitative interpretation of X-ray diffraction patterns of mixtures. I. Matrix-flushing method for quantitative multicomponent analysis." J. Appl. Cnpt. 7:519-525.

Glassley, W.E., and S. Boyd (1995). "Preliminary description of Small Block mineralogical features." Milestone report for the CRWMS Management and Operating Contractor, U.S. Department of Energy. (MOL062).

Hellman, R. (1994). “The albite-water system: Part I. The kinetics of dissolution as a function of $\mathrm{pH}$ at 100,200 , and $300^{\circ} \mathrm{C}$." Geochim. et Cosmochim. Acta 58(2):595-611.

Johnson, J.W., K.G. Knauss, W.E. Glassley, and L.D. DeLoach (1997a). "Reactive transport modeling of plug-flow-reactor experiments: significance, initial results, and future applications" Journal of Hydrology. (in press).

Johnson, J.W., K.G. Knauss, W.E. Glassley, and L.D. DeLoach (1997b). "Reactive transport through Topopah Spring Tuff: Summary of initial PFR experiments and associated computer simulations." Milestone report for the CRWMS Management and Operating Contractor, U.S.

Department of Energy. Livermore, CA: Lawrence Livermore National Laboratory.

Knauss, K. (1987). "Zeolitization of Glassy Topopah Spring Tuff under Hydrothermal Conditions." In proceedings from Materials Research Society Symposium. 84:737-745. (Also UCRL-94664, Lawrence Livermore National Laboratory, Livermore, CA).

Knauss, K.G., W.J. Beiriger, D.W. Peifer, and A.J. Piwinskii (1985). "Hydrothermal Interaction of Solid Wafers of Topopah Spring Tuff with J-13 Water and Distilled Water at 90,150 , and $250^{\circ} \mathrm{C}$, Using Dickson-Type, GoldBag Rocking Autoclaves." (UCRL-53645). Livermore, CA: Lawrence Livermore National Laboratory. 
Knauss, K.G., and S.A. Copenhaver (1995a). "The effect of malonate on the dissolution kinetics of albite, quartz, and microcline as a function of $\mathrm{pH}$ at $70^{\circ} \mathrm{C} . "$ Applied Geochemistry 10:17-33.

Knauss, K.G., and S.A. Copenhaver (1995b). "Progress Report on Hydrothermal Alteration of Vitric Tuff from Yucca Mountain." June 1955. Livermore, CA: Lawrence Livermore National Laboratory, Earth Sciences Division.

Knauss, K.G., J.M. Delany, W.J. Beiriger, and D.W. Peifer (1986). "Hydrothermal Interaction of Topopah Spring Tuff with J-13 Water as a Function of Temperature." In proceedings from Mat. Res. Soc. Symp. 44:539-546.

Knauss, K.G., and T.J. Wolery (1988). "The dissolution kinetics of quartz as a function of $\mathrm{pH}$ and time at $70^{\circ} \mathrm{C} . "$ Geochim. et Cosmochim. Acta 52(1).

Knauss, K.G., and T.J. Wolery (1989). "Muscovite dissolution kinetics as a function of $\mathrm{pH}$ and time at $70^{\circ} \mathrm{C}$." Geochim. et Cosmochim. Acta 53:1493-1501.

Nagy, K.L. (1995). "Dissolution and precipitation kinetics of sheet silicates." A.F. White and S. L. Brantley (eds). Chemical weathering rates of silicate minerals. Washington, DC: Min. Soc. Amer. 31:173-233.

Rafal'skiy, R.P., N.I. Prisyagina, and I.B. Kondrushin (1990). "Reaction of microcline-perthite with aqueous solutions at $150^{\circ}$ and $250^{\circ} \mathrm{C} . "$ Geochim Int 27:56-66.

Renders, P.J.N., C.H. Gammons, and H. L. Barnes (1995). "Precipitation and dissolution rate constants for cristobalite from 150 to $300^{\circ} \mathrm{C}$." Geochim. et Cosmochim. Acta 49(1):77-85.

Rimstidt, J.D., and H L. Barnes (1980). "The kinetics of silica-water reactions." Geochim. et Cosmochim. Acta 44:1683-1699.

Roberts, S., and B. Viani (1997a). “Mineral abundances for samples from instrumentation boreholes in the access drift scale test (DST) area of the ESF." Milestone report for the CRWMS Management and Operating Contractor, U.S. Department of Energy. (SP511M4). Livermore, CA: Lawrence Livermore National Laboratory.

Roberts, S., and B. Viani (1997b). "Mineral abundances for samples from six chemistry (SEAMIST) boreholes in the Drift Scale Test (DST) area of the ESF." Milestone report for the CRWMS Management and Operating Contractor, U.S. Department of Energy. (SP9510M4). Livermore, CA: Lawrence Livermore National Laboratory.

Steefel, C.I., and S.B. Yabusaki (1996). User's manual and programmer's guide, Version 1.0, for software for modeling multicomponent, multidimensional reactive transport. Richland, WA: Pacific Northwest National Laboratory. (Internal Report, $58 \mathrm{pp}$ ).

Stillings, L.L., J.I. Drever, S.L. Brantley, Y. Sun, and R. Oxburgh (1996). “Rates of feldspar dissolution at pH 3-7 with 0-8 m M oxalic acid." Chem Geo 132:79-89. 
Tester, J.W., W.G. Worley, B.A. Robinson, C.O. Grigsby, and J.R. Feerer (1994). "Correlating quartz dissolution kinetics in pure water from 25 to $625^{\circ} \mathrm{C}$." Geochim. et Cosmochim. Acta 58(11):2407-2420.

Vaniman, D., D. Bish, D. Broxton, F. Byers, G. Heiken, B. Carlos, E. Semarge, F. Caporuscio, and R. Gooley (1984). "Variations in Authigenic Mineralogy and Sorptive Zeolite Abundance at Yucca Mountain, Nevada, Based on Studies of Drill Cores USW GU-3 and G-3." June 1984. (LA-9707-MS). Los Alamos, NM: Los Alamos National Laboratory. (71 pp).

Welton, J.E. (1984). SEM Petrology Atlas. Tulsa, OK: AAPG. 
Table 1. Description of the starting materials used in plug-flow-reactor (PFR) experiments

\begin{tabular}{|c|c|c|c|c|}
\hline Experiment & PFR2 & PFR3 & PFR5 & PFR8 \\
\hline Plug Material & Supracil & quartz & TSw2 & TSw3 \\
\hline Source & Heraeus Amersil & $\begin{array}{l}\text { Red Horse Lake } \\
\text { Lyndhurst, Ontario }\end{array}$ & $\begin{array}{l}\text { Yucca Mtn., NV } \\
\text { USW G1 (1235') }\end{array}$ & $\begin{array}{l}\text { Yucca Mtn., NV } \\
\text { USW G3 (1216') }\end{array}$ \\
\hline Composition & $\mathrm{SiO}_{2}$ & $\mathrm{SiO}_{2}$ & rhyolitic tuff & rhyolitic tuff \\
\hline Texture & amorphous & single crystal & $\begin{array}{l}\text { devitrified, welded } \\
\text { (lithophysal-poor) }\end{array}$ & welded, vitric tuff \\
\hline Grain Size & $100 \pm 25 \mu \mathrm{m}$ & $100 \pm 25 \mu \mathrm{m}$ & $100 \pm 25 \mu \mathrm{m}$ & $100 \pm 25 \mu \mathrm{m}$ \\
\hline $\begin{array}{l}\text { Surface Area } \\
\text { BET }\left(\mathrm{m}^{2} / \mathrm{g}\right)^{\star}\end{array}$ & $\begin{array}{c}0.1200(\mathrm{Kr}) \\
0.097\left(\mathrm{~N}_{2}\right) \\
\end{array}$ & $0.0542(\mathrm{Kr})$ & $2.75\left(\mathrm{~N}_{2}\right)$ & $0.611\left(\mathrm{~N}_{2}\right)$ \\
\hline $\begin{array}{l}\text { Initial Bulk } \\
\text { Porosity (vol \%) }\end{array}$ & 42.5 & 42.5 & 42.5 & 42.5 \\
\hline $\begin{array}{l}\text { Initial Bulk } \\
\text { Porosity (calc.) } \\
\text { (vol \%) }\end{array}$ & 59 & 62 & 51 & 58 \\
\hline
\end{tabular}

${ }^{*} \mathrm{Kr}=$ krypton gas adsorption; $\mathrm{N}_{2}=$ nitrogen gas adsorption

Table 2. Experiment parameters for the plug-flow-reactor studies

\begin{tabular}{|c|c|c|c|c|}
\hline Experiment & PFR2 & PFR3 & PFR5 & PFR8 \\
\hline $\begin{array}{l}\text { Starting } \\
\text { Material }\end{array}$ & Supracil & quartz & TSw2 & TSw3 \\
\hline Inlet Fluid & deionized water & deionized water & deionized water & deionized water \\
\hline $\begin{array}{l}\text { Plug Length } \\
(\mathrm{cm})\end{array}$ & 3.1 & 3.1 & 26.3 & 30.3 \\
\hline $\begin{array}{l}\text { Plug Diameter } \\
(\mathrm{cm})\end{array}$ & 0.656 & 0.656 & 0.656 & 0.656 \\
\hline Duration (days) & 5.9 & 12.7 & 36 & 42 \\
\hline Pressure (psi) & $750-800$ & $750-800$ & $650-750$ & $1100-1300$ \\
\hline $\begin{array}{l}\text { Steady-State } \\
\text { Temperature } \\
\left({ }^{\circ} \mathrm{C}\right)\end{array}$ & 238 & 239 & 240 & 250 \\
\hline $\begin{array}{l}\text { Average Flow } \\
\text { Rate (m//day) }\end{array}$ & 26.4 & 24.8 & 25.0 & 26.5 \\
\hline
\end{tabular}

Average of values measured each time effluent fluid was sampled for compositional analysis 
Table 3. Summary of basal vitrophyre (TSw3) mineralogy as determined and simulated in this study

\begin{tabular}{|c|c|c|c|c|}
\hline \multirow[t]{2}{*}{ Mineral } & \multirow[t]{2}{*}{ Mineral Composition } & \multicolumn{3}{|c|}{ Volume Fraction (\%) } \\
\hline & & Actual $^{a}$ & Model $^{\mathrm{b}}$ & Model ${ }^{\circ}$ \\
\hline Glass & see footnote ${ }^{d}$ & 87.00 & 87.00 & 50.0250 \\
\hline Alkali feldspar & approx. $\mathrm{Or}_{50} \mathrm{Ab}_{50}$ & 4.00 & - & - \\
\hline Plagioclase & approx. $A b_{50} A n_{50}$ & 4.00 & - & - \\
\hline Biotite & $\mathrm{K}(\mathrm{Fe}, \mathrm{Mg})_{3} \mathrm{AlSi}_{3} \mathrm{O}_{10}(\mathrm{OH})_{2}$ & 1.00 & - & - \\
\hline Magnetite & $\mathrm{Fe}_{3} \mathrm{O}_{4}$ & 1.00 & 1.00 & 0.5750 \\
\hline Quartz & $\mathrm{SiO}_{2}$ & 1.50 & 1.50 & 0.8625 \\
\hline Cristobalite & $\mathrm{SiO}_{2}$ & 1.50 & 1.50 & 0.8625 \\
\hline Albite & $\mathrm{NaAlSi}_{3} \mathrm{O}_{\mathrm{g}}$ & - & 4.00 & 2.3000 \\
\hline Anorthite & $\mathrm{CaAl}_{2} \mathrm{Si}_{2} \mathrm{O}_{8}$ & - & 2.00 & 1.1500 \\
\hline K-feldspar & $\mathrm{KAISi}_{3} \mathrm{O}_{8}$ & - & 2.00 & 1.1500 \\
\hline Annite & $\mathrm{KFe}_{2} \mathrm{AlSi}_{3} \mathrm{O}_{10}(\mathrm{OH})_{2}$ & - & 0.50 & 0.2875 \\
\hline Phlogopite & $\mathrm{KMg}_{3} \mathrm{AlSi}_{3} \mathrm{O}_{10}(\mathrm{OH})_{2}$ & - & 0.50 & 0.2875 \\
\hline & Total & 100.00 & 100.00 & 57.5000 \\
\hline
\end{tabular}

a this study

${ }^{b} 0 \%$ porosity

c $42.5 \%$ porosity

d This fictive 8-oxygen glass phase is based on microprobe analyses of the basal vitrophyre from drillhole USW GU-3 (1227 ft) given by Vaniman et al. (1984). 
Table 4. Summary of mineral-specific surface areas, elevated-temperature and reference-state dissolution/precipitation rate constants, and activation energies adopted in GIMRT simulations of PFR8

\begin{tabular}{|c|c|c|c|c|}
\hline Mineral & $A_{m}{ }^{\prime}$ & $r_{m}, 250^{\circ} \mathrm{C}^{\mathrm{b}}$ & $r_{m}, P_{n} T_{r}^{\mathrm{b}}$ & $E a^{c}$ \\
\hline Glass & $6106^{d}$ & $0.3631\left(10^{-8}\right)^{8}$ & - & - \\
\hline Quartz & $542^{4}$ & $0.4201\left(10^{-7}\right)^{9}$ & - & - \\
\hline Cristobalite & $542^{h}$ & $0.5368\left(10^{-7}\right)^{i}$ & - & - \\
\hline K-feldspar & $1086^{1}$ & $0.3631\left(10^{-8}\right)^{i}$ & - & - \\
\hline Albite & $795^{4}$ & $0.1122\left(10^{-6}\right)^{x}$ & - & - \\
\hline Anorthite & $950^{\prime}$ & $0.1122\left(10^{-3}\right)^{m}$ & - & - \\
\hline Magnetite & 1000 & $0.4043\left(10^{-8}\right)^{n}$ & $10^{-13}$ & 15.0 \\
\hline Annite & $11000^{\circ}$ & $0.1994\left(10^{-9}\right)^{n}$ & $10^{-140}$ & $14.0^{\circ}$ \\
\hline Phlogopite & $11000^{\circ}$ & $0.1994\left(10^{-9}\right)^{n}$ & $10^{-140}$ & $14.0^{p}$ \\
\hline Muscovite & - & $0.1994\left(10^{-9}\right)^{n}$ & $10^{-14 p}$ & $14.0^{p}$ \\
\hline Paragonite & - & $0.1994\left(10^{-9}\right)^{n}$ & $10^{-140}$ & $14.0^{n}$ \\
\hline Kaolinite & - & $0.4043\left(10^{-8}\right)^{n}$ & $10^{-13 q}$ & $15.0^{9}$ \\
\hline Pyrophyllite & - & $0.4043\left(10^{-8}\right)^{n}$ & $10^{-139}$ & $15.0^{9}$ \\
\hline Gibbsite & - & $0.1213\left(10^{-7}\right)^{n}$ & $3\left(10^{-13}\right)^{4}$ & $15.0^{9}$ \\
\hline Diaspore & - & $0.1213\left(10^{-7}\right)^{n}$ & $3\left(10^{-13}\right)^{r}$ & $15.0^{r}$ \\
\hline Boehmite & - & $0.1213\left(10^{-7}\right)^{n}$ & $3\left(10^{-13}\right)^{r}$ & $15.0^{r}$ \\
\hline Illite & - & $0.4043\left(10^{-8}\right)^{n}$ & $10^{-13}$ & 15.0 \\
\hline Smectite-high-Fe-Mg & - & $0.4043\left(10^{-8}\right)^{n}$ & $10^{-13}$ & 15.0 \\
\hline Smectite--low-Fe-Mg & - & $0.4043\left(10^{-8}\right)^{n}$ & $10^{-13}$ & 15.0 \\
\hline Clinoptilolite-Na & - & $0.4043\left(10^{-8}\right)^{n}$ & $10^{-13}$ & 15.0 \\
\hline Clinoptilolite-K & - & $0.4043\left(10^{-8}\right)^{n}$ & $10^{-13}$ & 15.0 \\
\hline
\end{tabular}

${ }^{2} \mathrm{~cm}^{2} \mathrm{~g}^{-1}$

${ }^{b} \mathrm{~mol} \mathrm{~m}^{-2} \mathrm{~s}^{-1}$

${ }^{\mathrm{c}} \mathrm{kcal} \mathrm{mol}^{-1}$

'this study

' estimated as equivalent to K-feldspar; see text

' Knauss and Copenhaver (1995a)

${ }^{8}$ Tester et al. (1994)

${ }^{\mathrm{h}}$ estimated as equivalent to quartz

' Renders et al. (1995)

' from data reported by Rafal'skiy et al. (1990) for microcline dissolution at $250^{\circ} \mathrm{C}$ (Hellman, 1994)

${ }^{k}$ Hellman (1994)

${ }^{1}$ Stillings et al. (1996)

${ }^{m}$ estimated relative to albite data (e.g., Blum and Stillings [1995])

${ }^{n}$ calculated from $r_{m}, P_{r}, T_{r}$ and $E_{a}$

- estimated as equivalent to muscovite (Knauss and Wolery, 1989)

${ }^{\mathrm{P}}$ Knauss and Wolery (1989)

${ }^{q}$ Nagy (1995)

' estimated as equivalent to gibbsite 
Table 5. PFR8 and GIMRT-predicted final outlet fluid composition reported as total ppm element (simulations $\mathrm{A}-\mathrm{F}$ are described in the text)

\begin{tabular}{|c|c|c|c|c|c|c|c|c|}
\hline \multirow[t]{2}{*}{ Run } & \multicolumn{2}{|c|}{$r_{m}, 250^{\circ} \mathrm{C}$} & \multirow[t]{2}{*}{$\begin{array}{l}\text { Saturation } \\
\text { threshold }\end{array}$} & \multicolumn{5}{|c|}{$\begin{array}{c}\text { Concentration (total ppm } \\
\text { element) }\end{array}$} \\
\hline & Primary & Secondary & & Si & $\mathrm{Na}$ & Al & $\mathbf{K}$ & $\mathrm{Ca}$ \\
\hline PFR8 & - & - & - & 417.1 & 47.4 & 22.2 & 14.2 & 0.1 \\
\hline A & $\mathrm{T} 4$ & T4 & - & 235.7 & 15.0 & 8.8 & 6.3 & $<<0.1$ \\
\hline B & T4 & T4 & $\mathrm{Q}, \mathrm{Cr}, \mathrm{Ab}$ & 343.0 & 45.7 & 24.9 & 1.0 & $<<0.1$ \\
\hline C & T4; glass $(x 10)$ & T3 & $\mathrm{Q}, \mathrm{Cr}, \mathrm{Ab}$ & 160.6 & 23.9 & 20.7 & 3.0 & $<<0.1$ \\
\hline D & T4 & T4 & $\mathrm{Q}, \mathrm{Ab}, \mathrm{Cr}, \mathrm{Kf}$ & 399.3 & 33.7 & 24.9 & 52.1 & $<<0.1$ \\
\hline$E$ & $\mathrm{~T} 4$ & T4 & $\mathrm{Q}, \mathrm{Ab}, \mathrm{Cr}, \mathrm{Mu}$ & 341.9 & 45.8 & 25.2 & 1.0 & $<<0.1$ \\
\hline $\mathrm{F}$ & $T_{4}$ & $T_{4}$ & $\mathrm{Q}, \mathrm{Ab}, \mathrm{Cr}, \mathrm{Mu}, \mathrm{Ka}, \mathrm{Py}$ & 343.3 & 45.6 & 25.3 & 1.0 & $<<0.1$ \\
\hline
\end{tabular}

a Primary minerals and their abundances in the actual and modeled basal vitrophyre are given in Table 3; reaction rate constants adopted herein are provided in Table 4 (T4); " $(x 10)^{\prime \prime}$ indicates that the reaction rate of the listed species has been increased one order of magnitude beyond its Table-4 value for the given simulation.

- Secondary minerals are those not listed in Table 3, but are included in Table 4; $\mathrm{Mu}=$ muscovite; $\mathrm{Ka}=$ kaolinite; $\mathrm{Py}=$ pyrophyllite; " $(\mathrm{x} 10)$ " indicates that the reaction rate of the listed species has been increased one order of magnitude beyond its Table-4 value for the given simulation.

c The saturation threshold $(\log (\mathrm{Q} / \mathrm{K})$ required for precipitation) of these species has been elevated above the maximum value attained for the given simulation; i.e., their precipitation has been suppressed. ( $\mathrm{Q}=$ quartz; $\mathrm{Cr}=$ cristobalite; $\mathrm{Ab}=$ albite; $\mathrm{Kf}=\mathrm{K}$-feldspar; $\mathrm{Mu}=$ muscovite) 
Figure 1. Evolution of $\mathrm{Si}$ concentration in PFR2 and PFR3: $\mathrm{SiO}_{2}-\mathrm{H}_{2} \mathrm{O}$ system

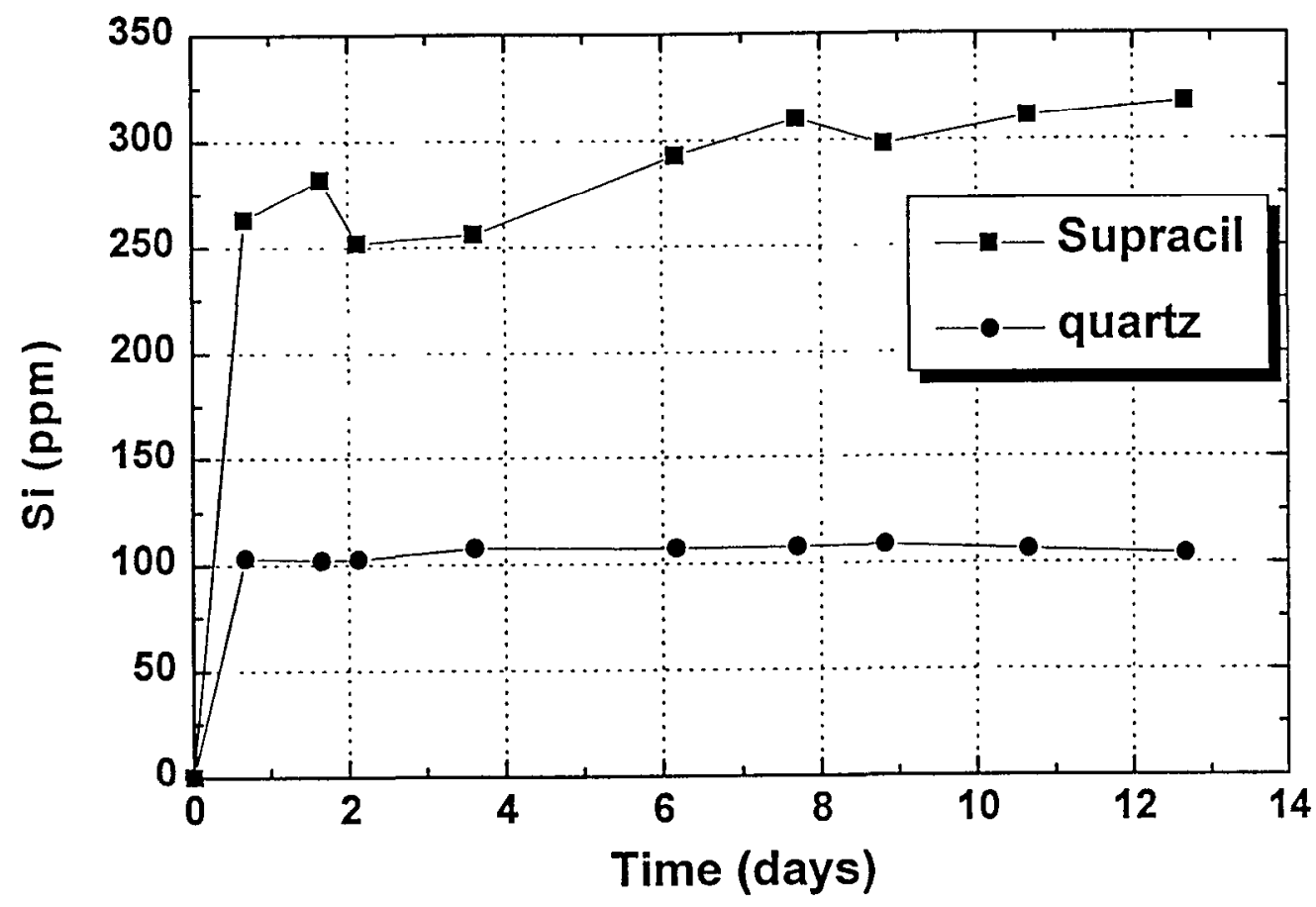


Figure 2. Evolution of fluid composition from PFR5: the devitrified tuff

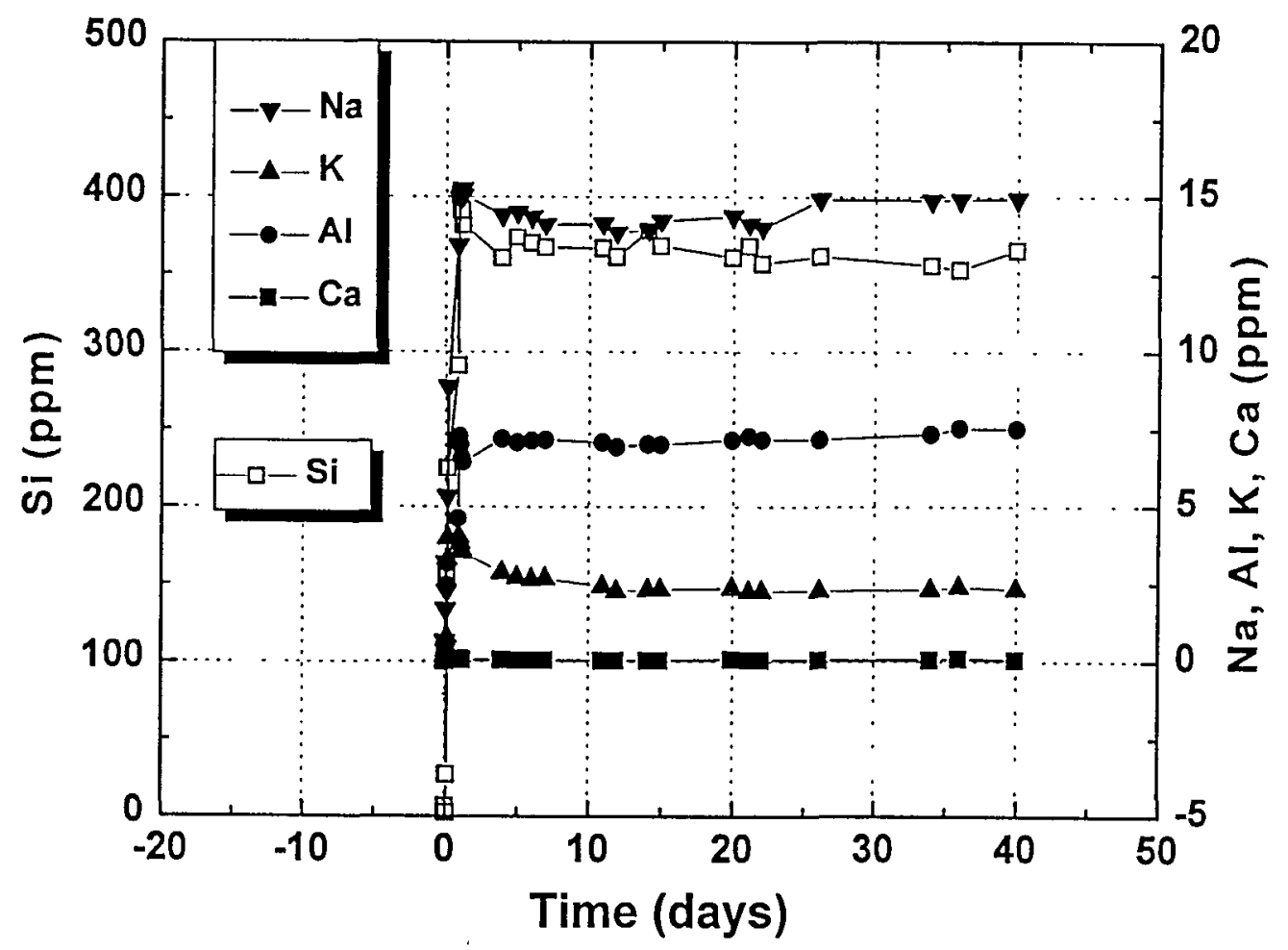


Figure 3. Evolution of fluid composition from PFR8: the vitric tuff

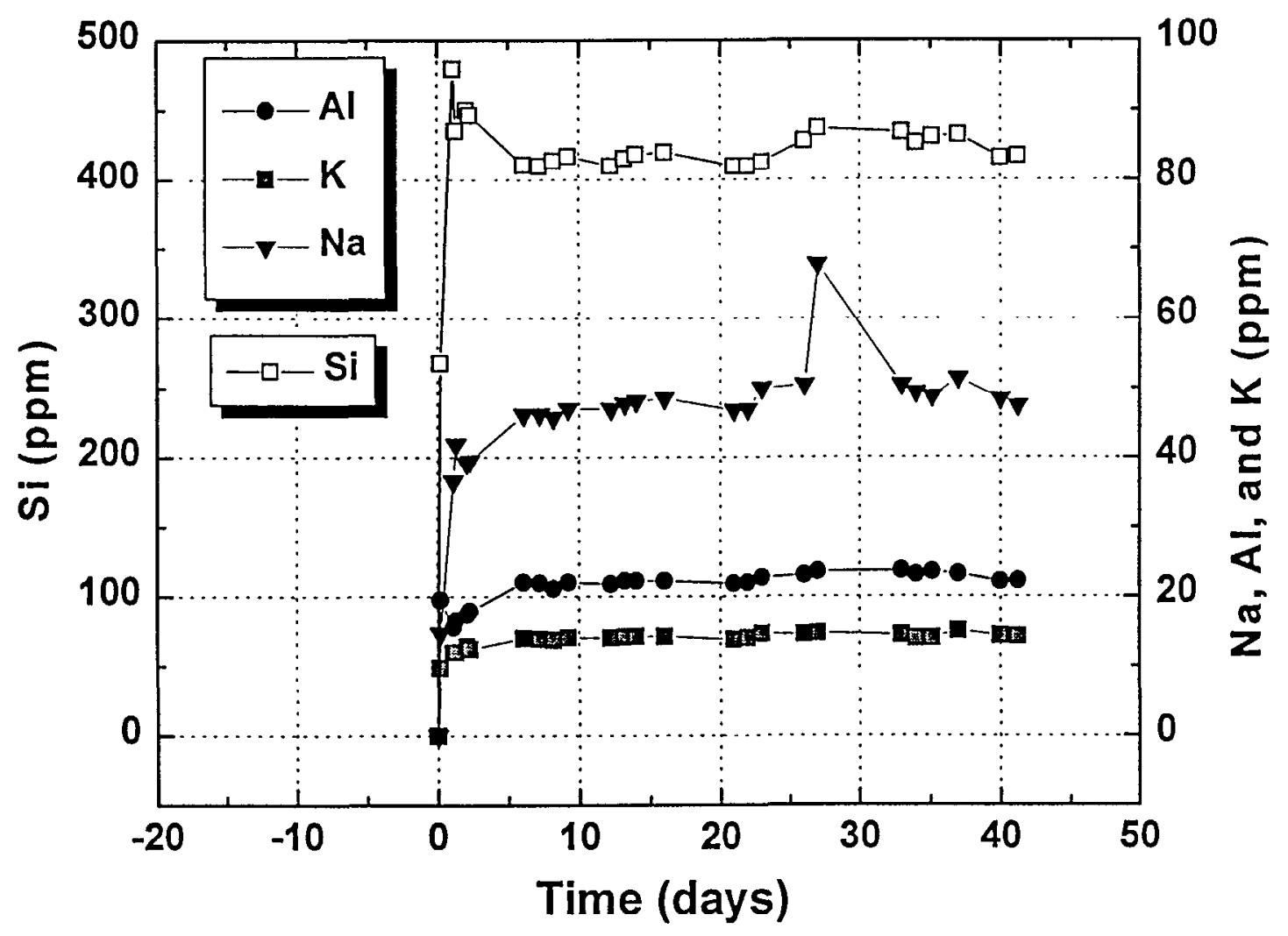


Figure 4. Anion chemistry from PFR8 fluid

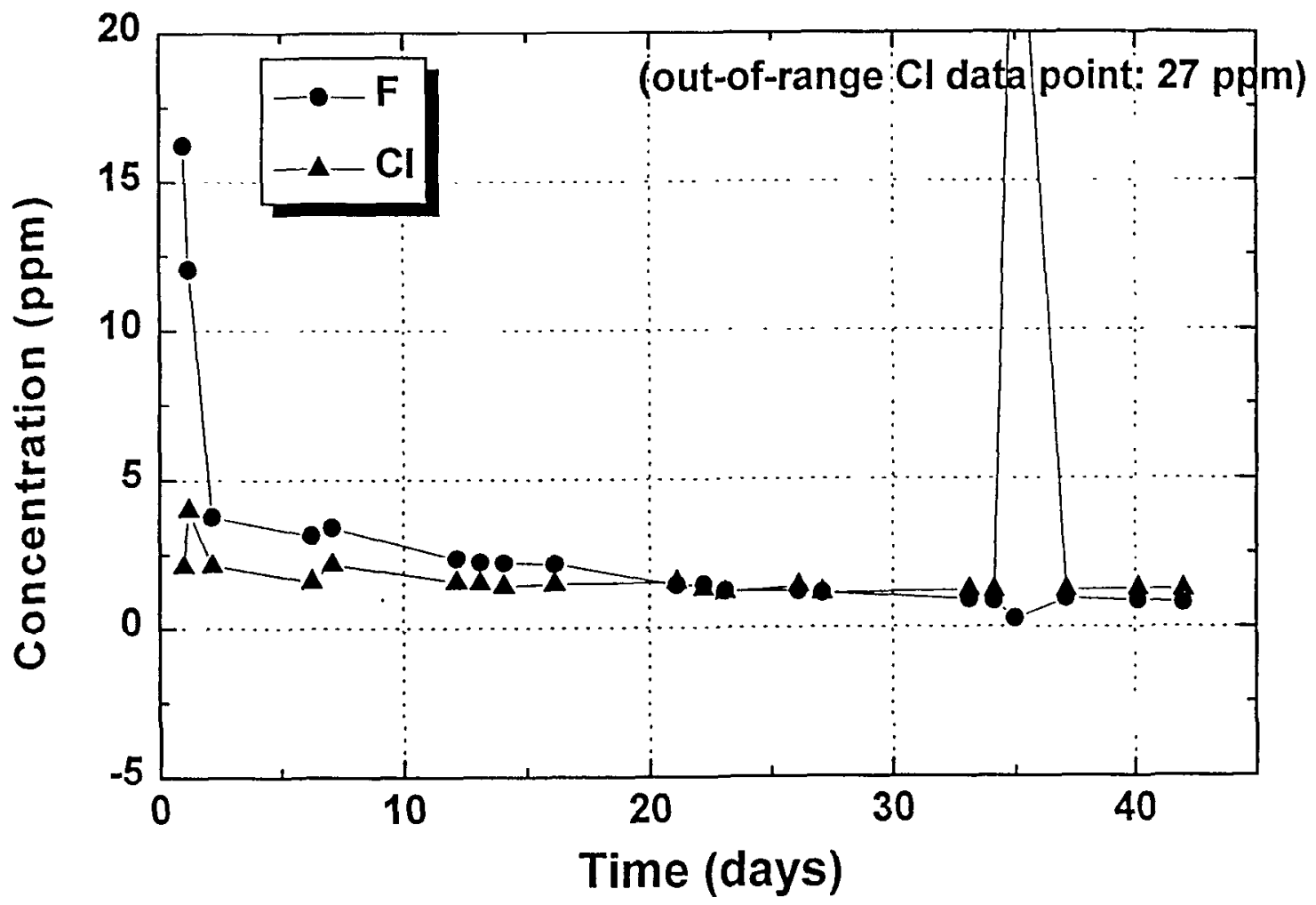


Figure 5. Evolving $\mathrm{pH}$ from tuff $-\mathrm{H}_{2} \mathrm{O}$ interactions

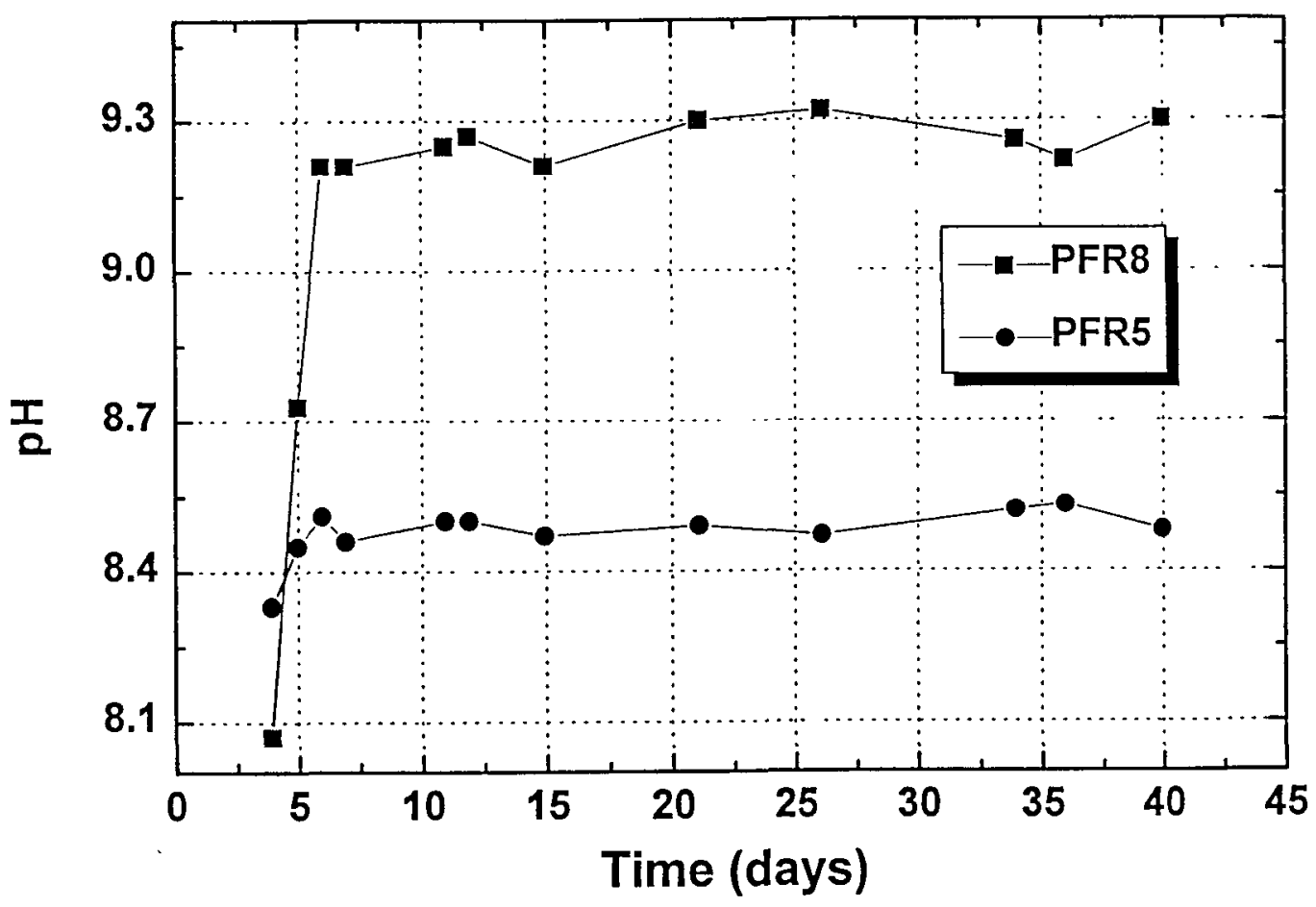


Modeling Changes in Mineral Assemblages and Sorptive Capaclty within the Altered Zone

Figure 6. X-ray diffraction results from PFR5: devitrified tuff

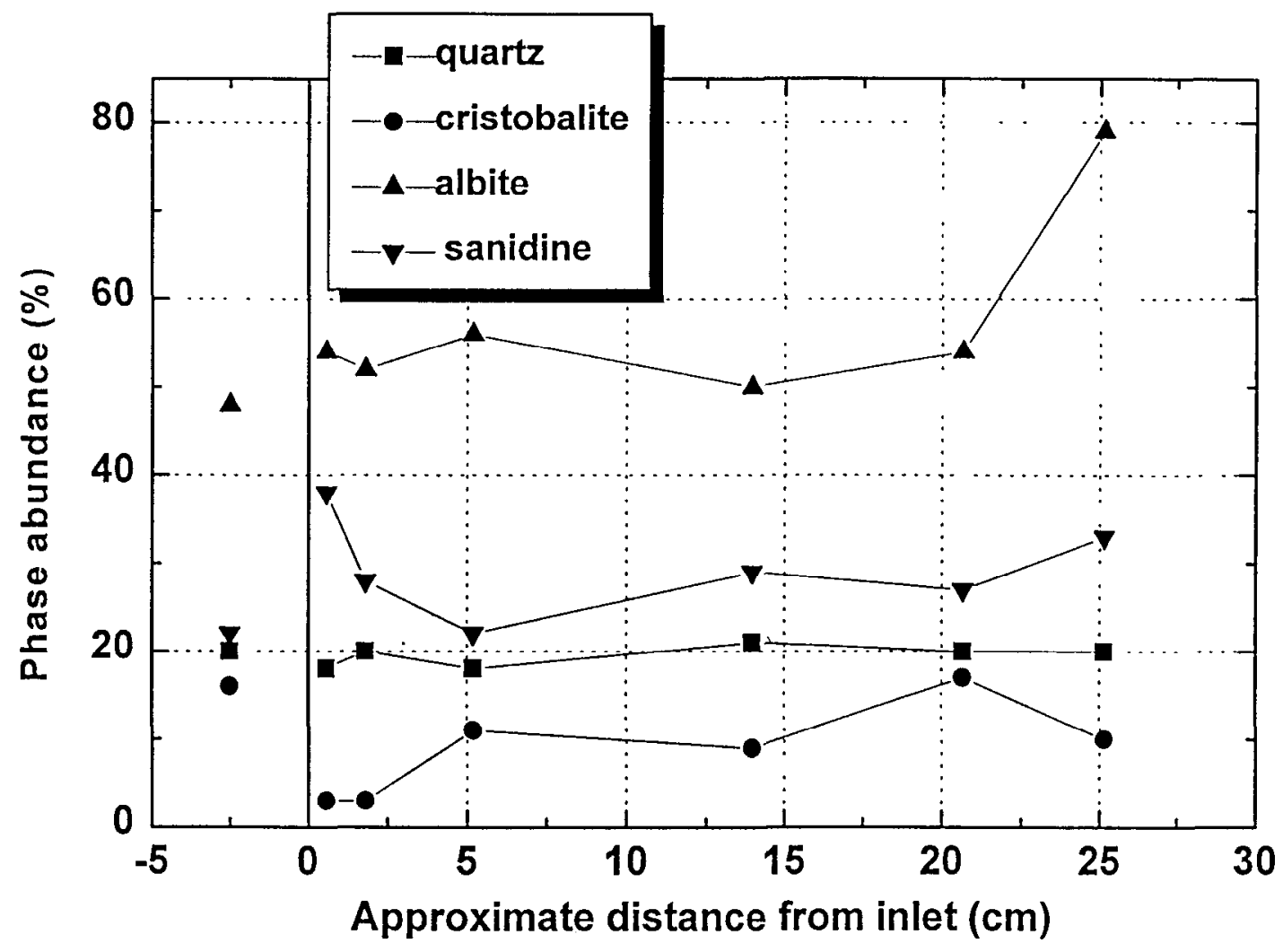


Figure 7a. SEM photograph of a primary alkali feldspar fragment with well-developed cleavage faces and intergrown regions of fine-grained silica polymorphs (from sample PFR5-Z)

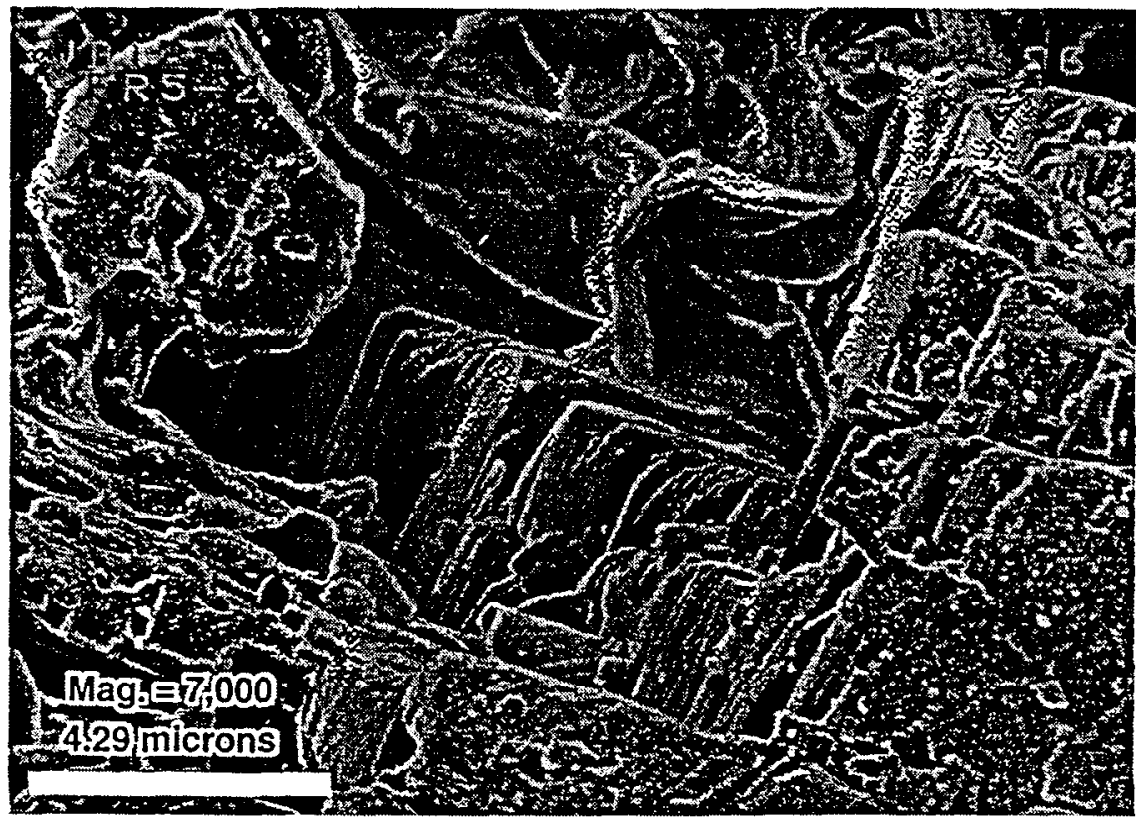

b. X-ray spectrum of approximately corresponding region: consistent with a K-rich alkali feldspar

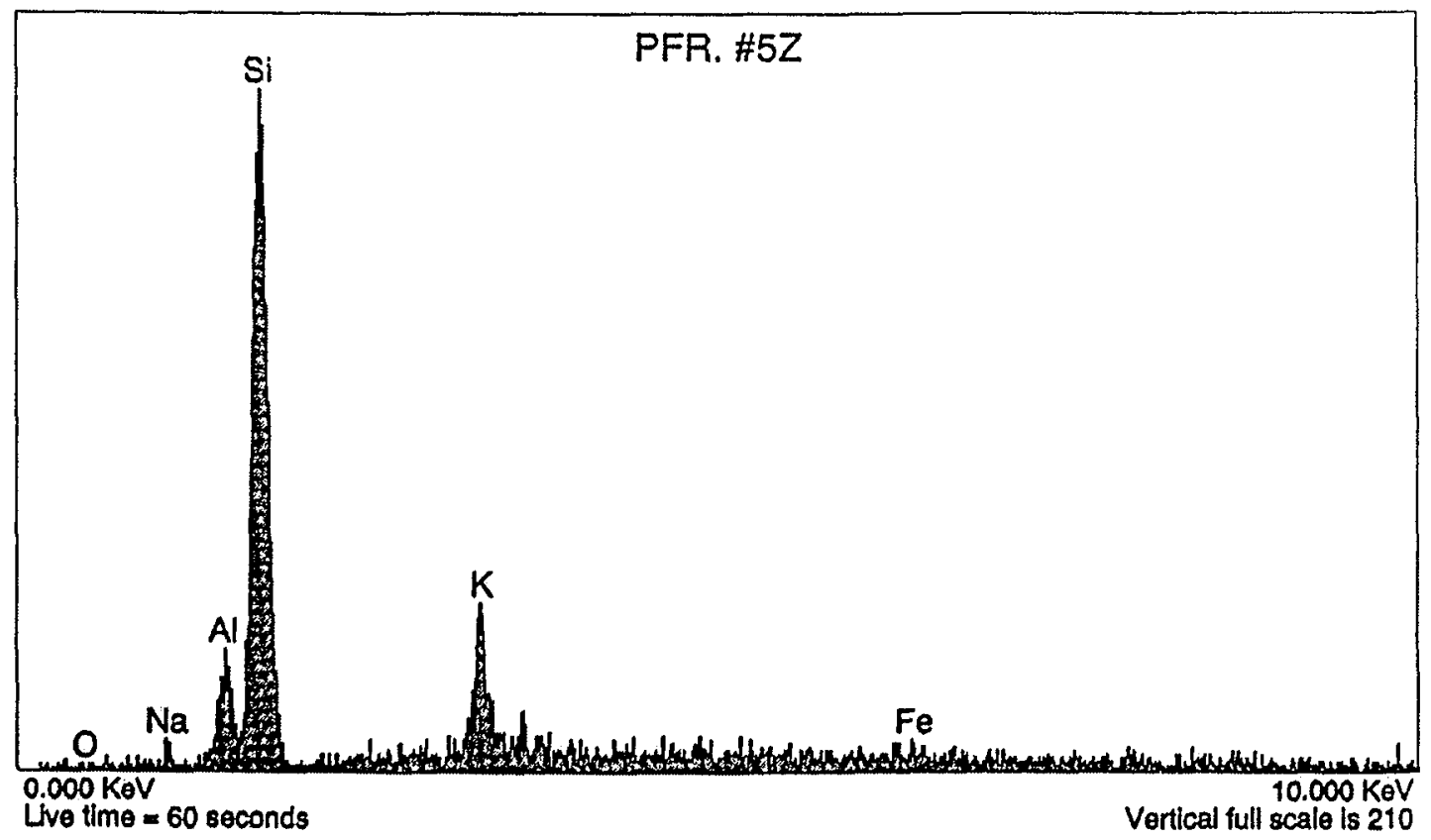


Modeling Changes in Mineral Assemblages and

Sorptive Capacity within the Altered Zone

Figure 8. Magnified view (portion of Fig.7a) showing the rough-surface characteristic of the fine-grained silica matrix

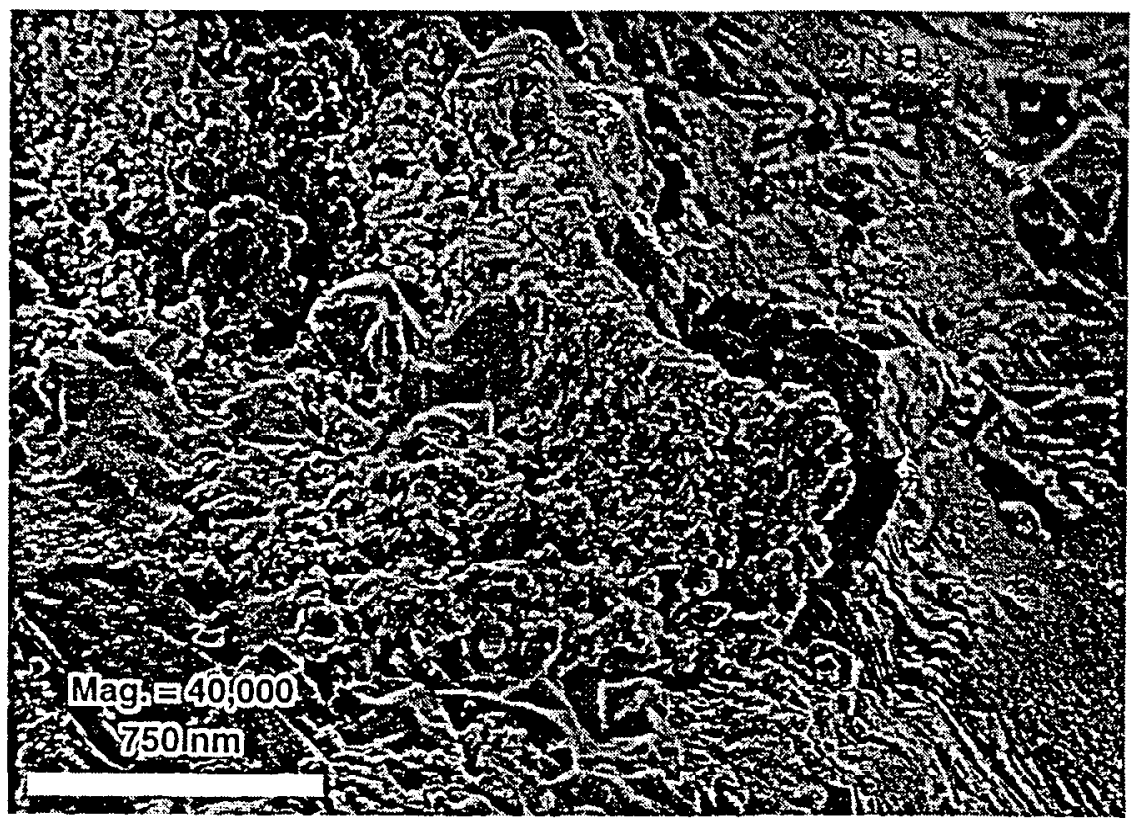


Figure 9. SEM photograph of a fresh cleavage surface of biotite (from sample PFR5-Z)

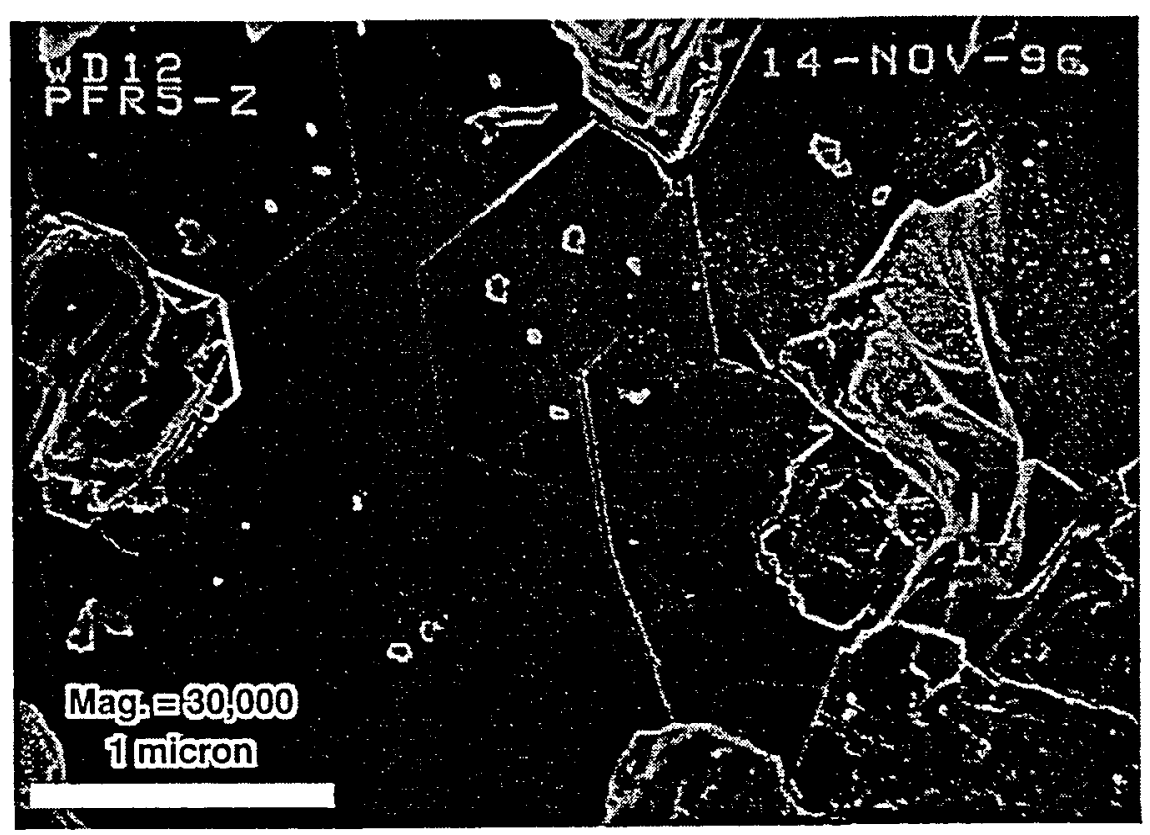


Modeling Changes in Mineral Assemblages and

Sorptive Capacity within the Altered Zone

Figure 10. SEM photograph of an alkali feldspar grain exhibiting pronounced dissolution features: preferential removal of material along cleavage planes, rounding of corners and surface etch pits (PFR5-A (inlet) sample)

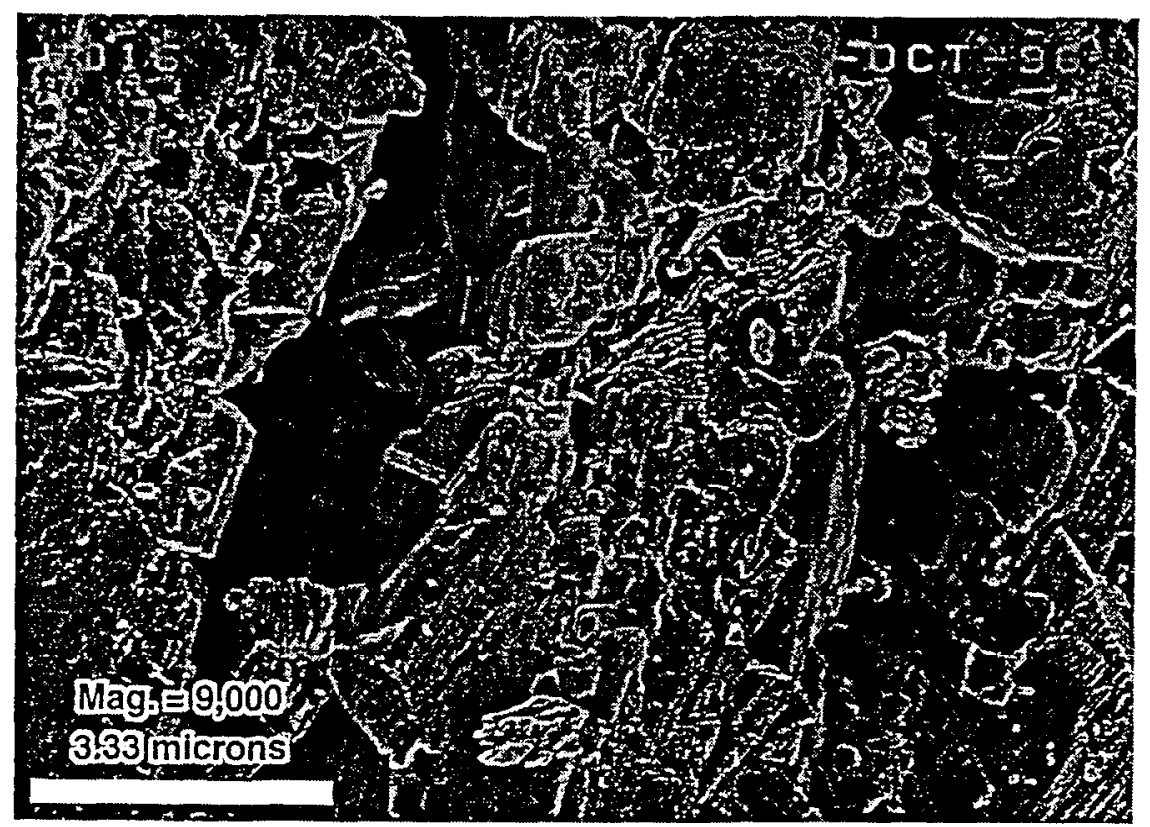


Figure 11a. SEM photograph of alkali feldspar; texture suggests remnant material after active , leaching (PFR5-A sample)

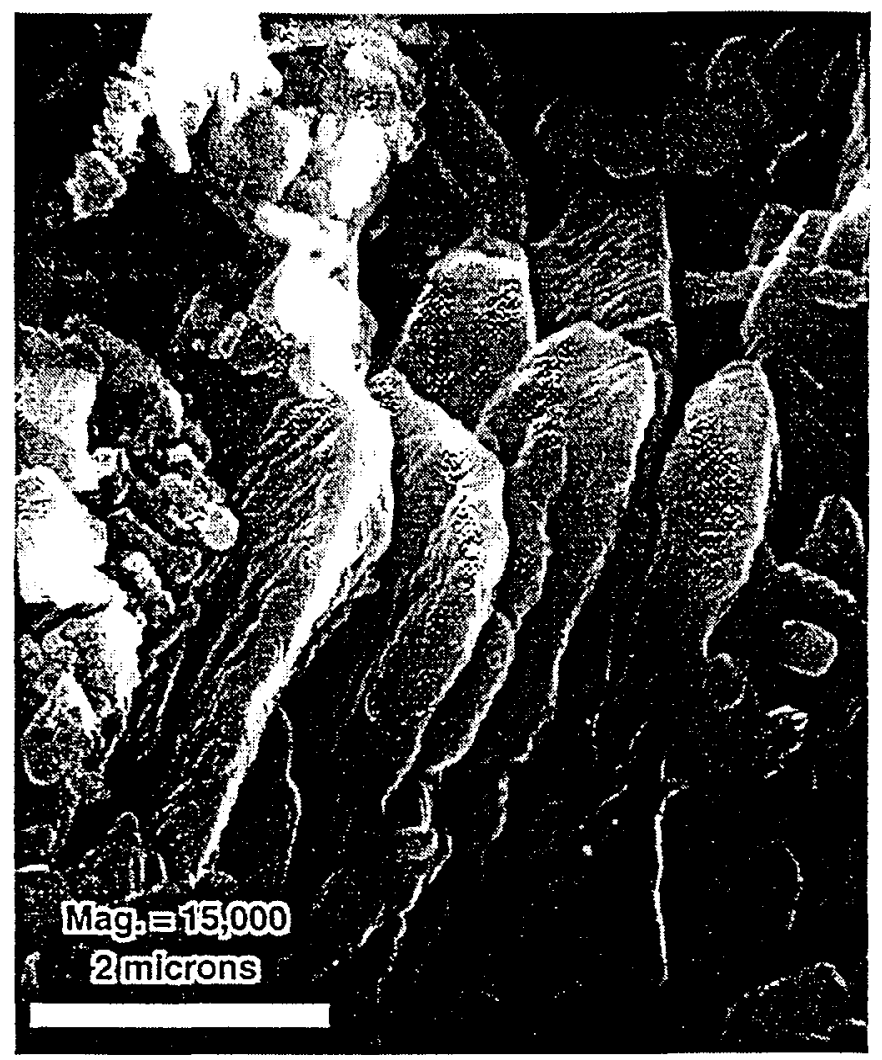

b. X-ray spectrum corresponding to $11 \mathrm{~A}$; consistent with $\mathrm{K}$-rich alkali feldspar

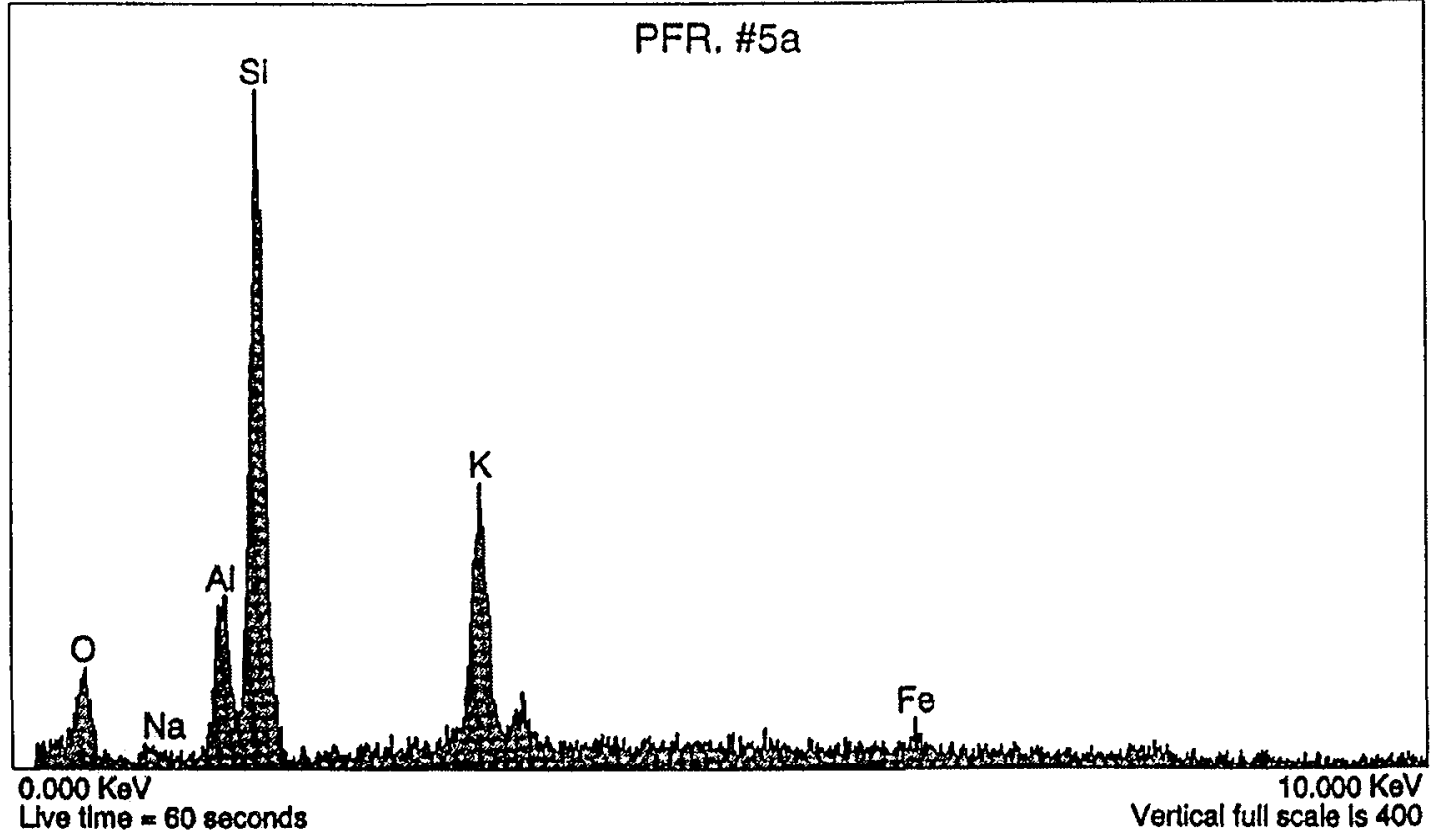


Figure 12. SEM photograph of Fe-rich rod resting on an etched K-rich alkali feldspar (PFR5A); probably hematite found in starting material

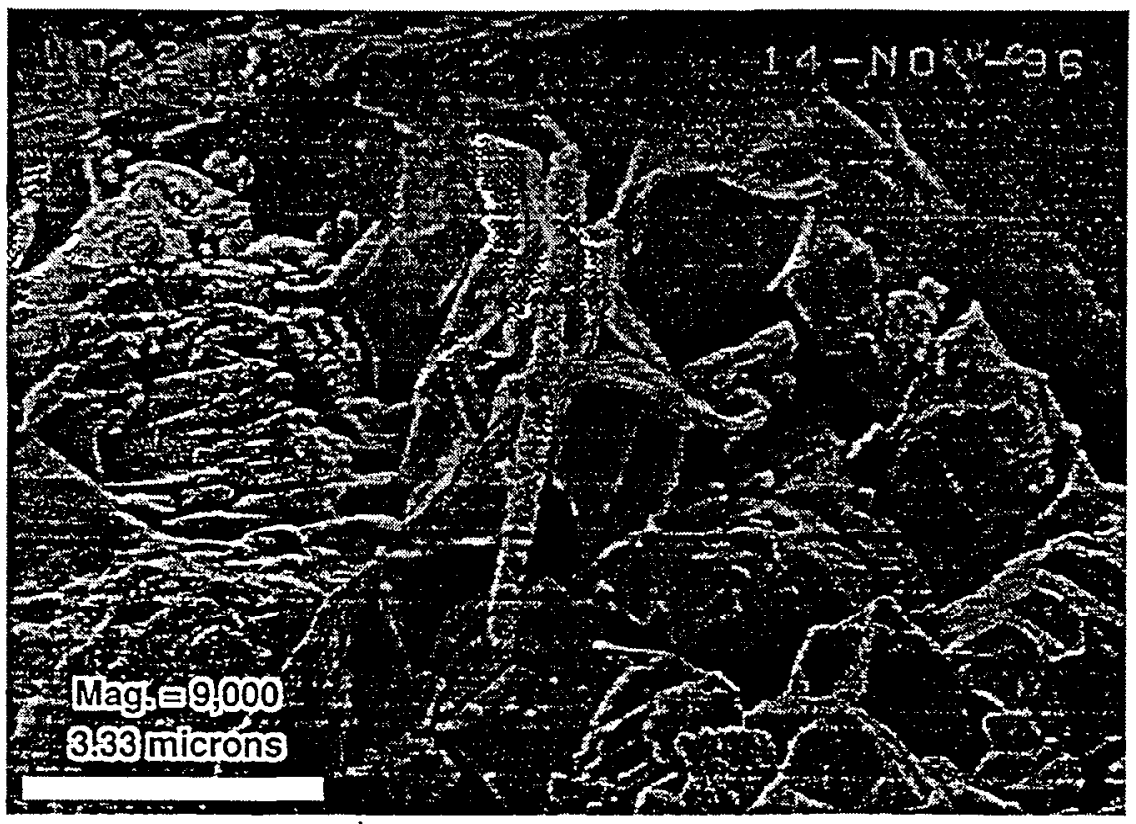


Figure 13. SEM photograph of the etched surface of a K-rich alkali feldspar grain from sample closest to fluid outlet, PFR5-M; dissolution texture less pronounced than patterns observed from samples collected higher in the flow path

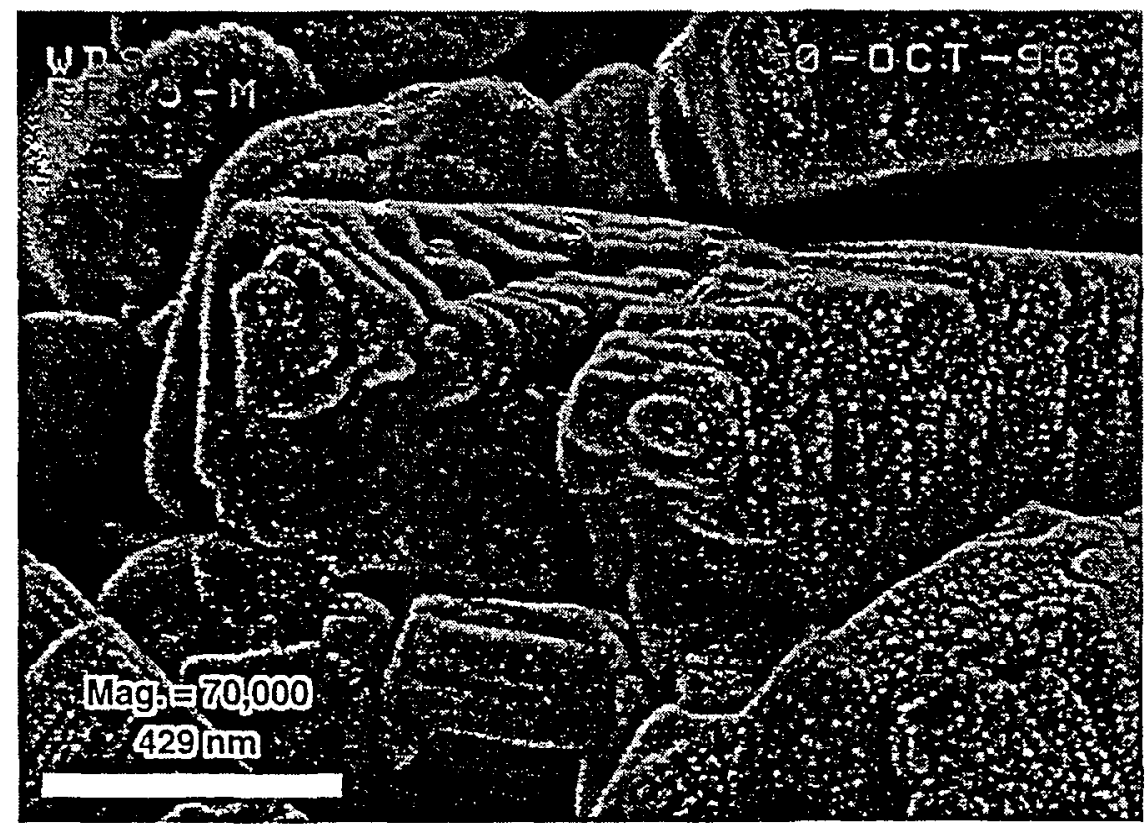


Figure 14. SEM photograph of a K-rich alkali feldspar, interpreted as perthitic texture - note the enhanced appearance of cleavage traces and contact areas between exsolved (?) and host minerals, presumably the result of dissolution (sample PFR5-M)

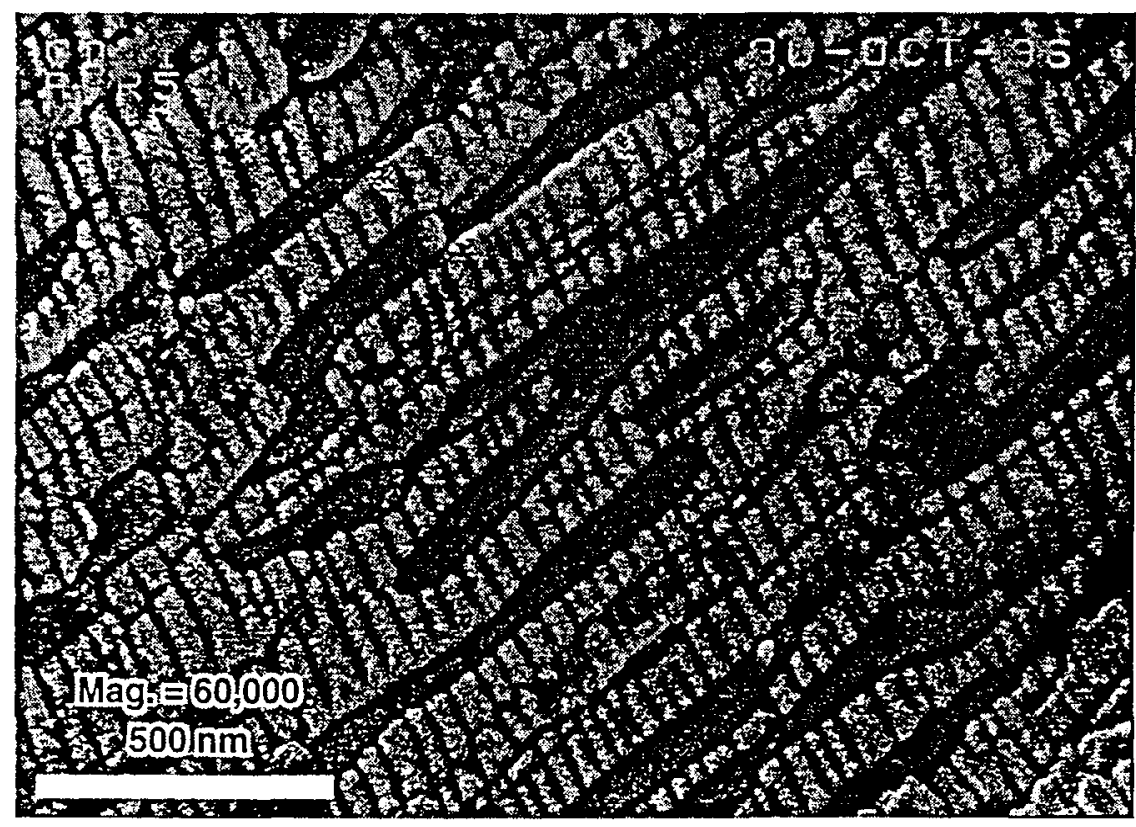


Figure 15a. SEM photograph of a plagioclase feldspar (PFR5-M); texture suggests twinning, with differential dissolution of the plagioclase on different faces of the twins

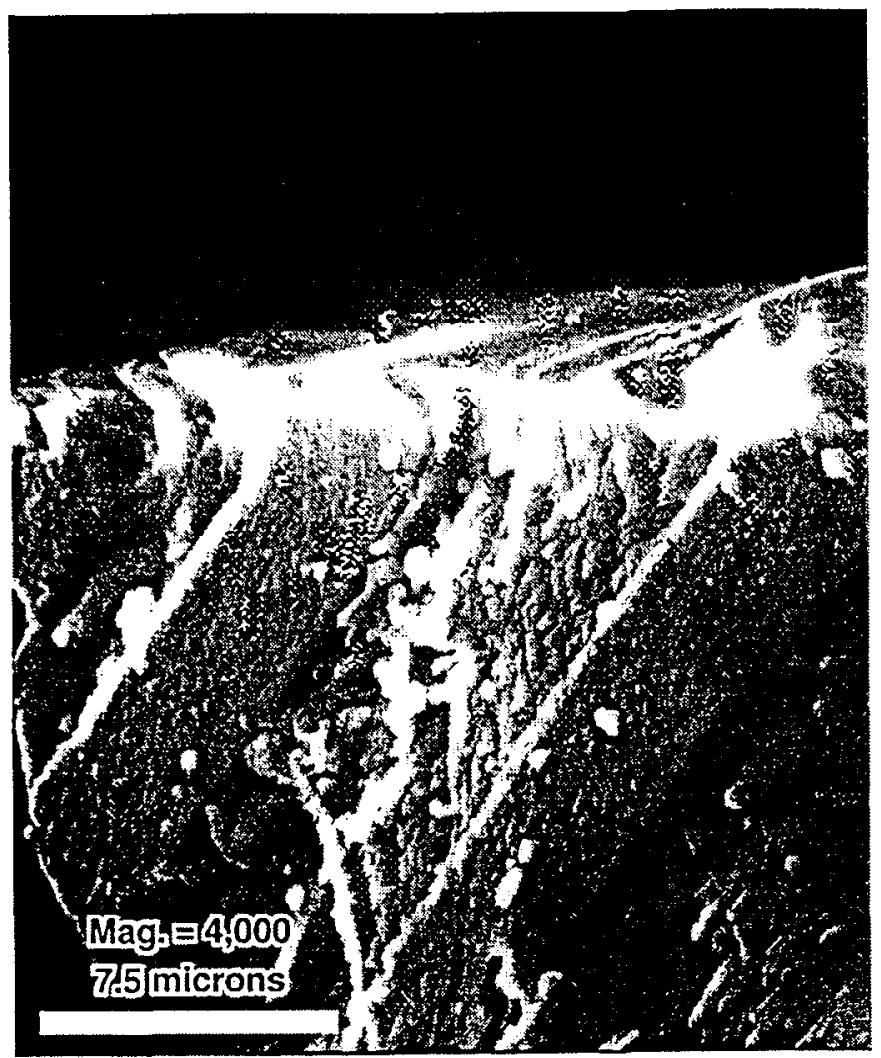

b. The X-ray spectra from the different plagioclase twin faces reveal similar chemistry
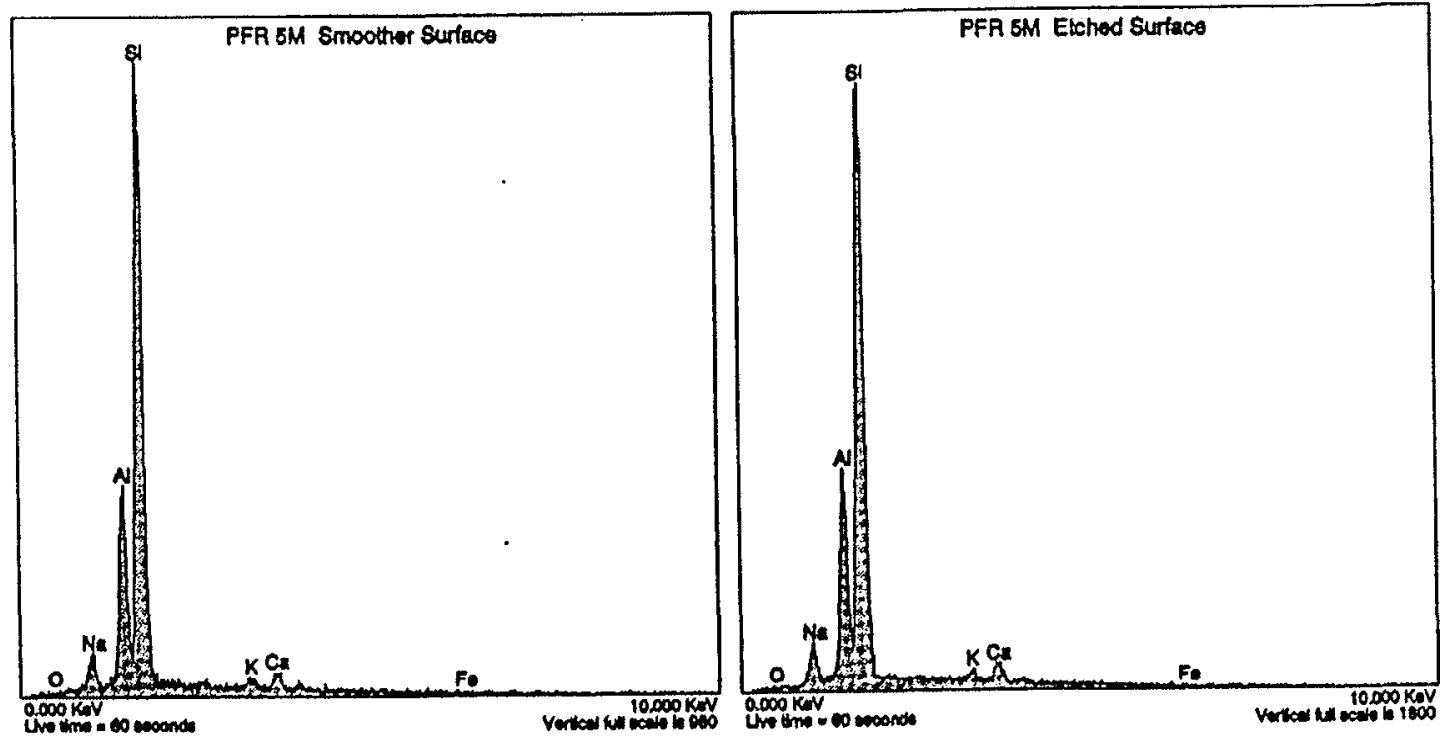
Figure 16a. SEM photograph of spherical silica phase; believed to be a precipitate in the sample nearest the fluid outlet, PFR5-M

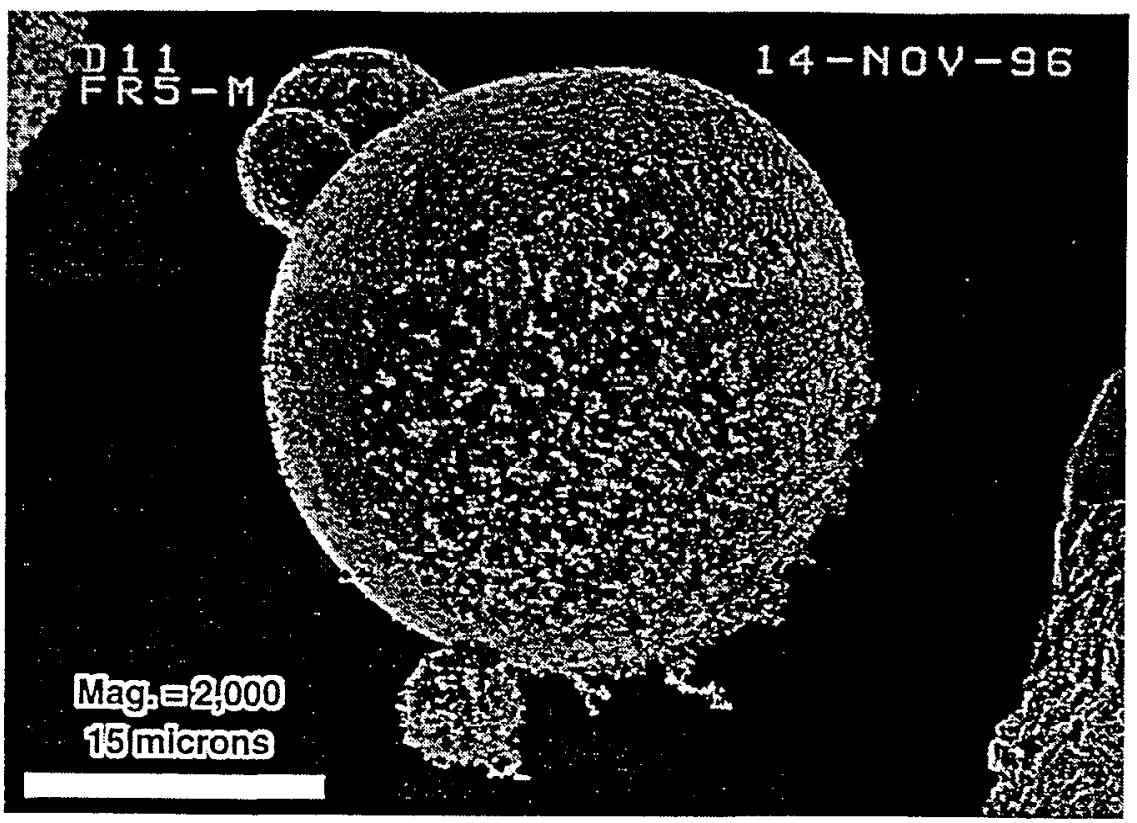

b. A magnified view of the silica spheres' surfaces

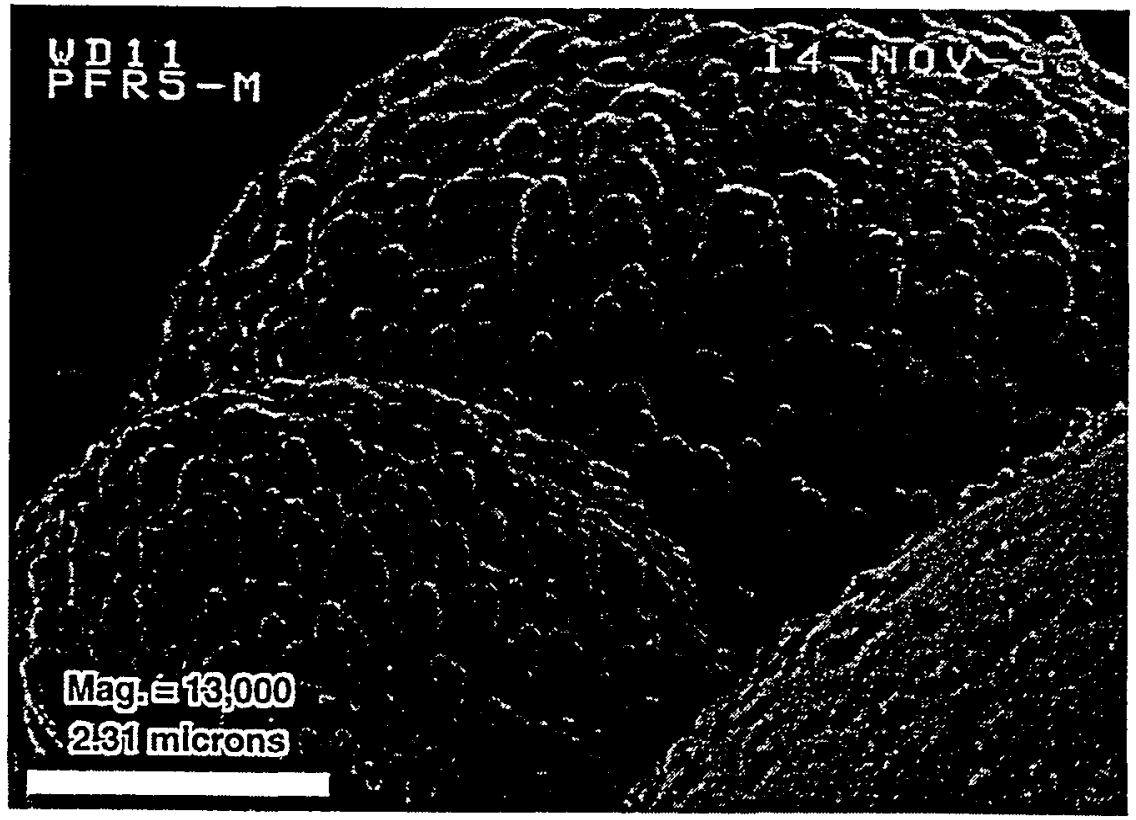


Figure 17. SEM photograph of unidentified phases exhibiting poor crystalline morphology similar to claylike phases; seen here resting on an alkali feldspar (PFR5-M)

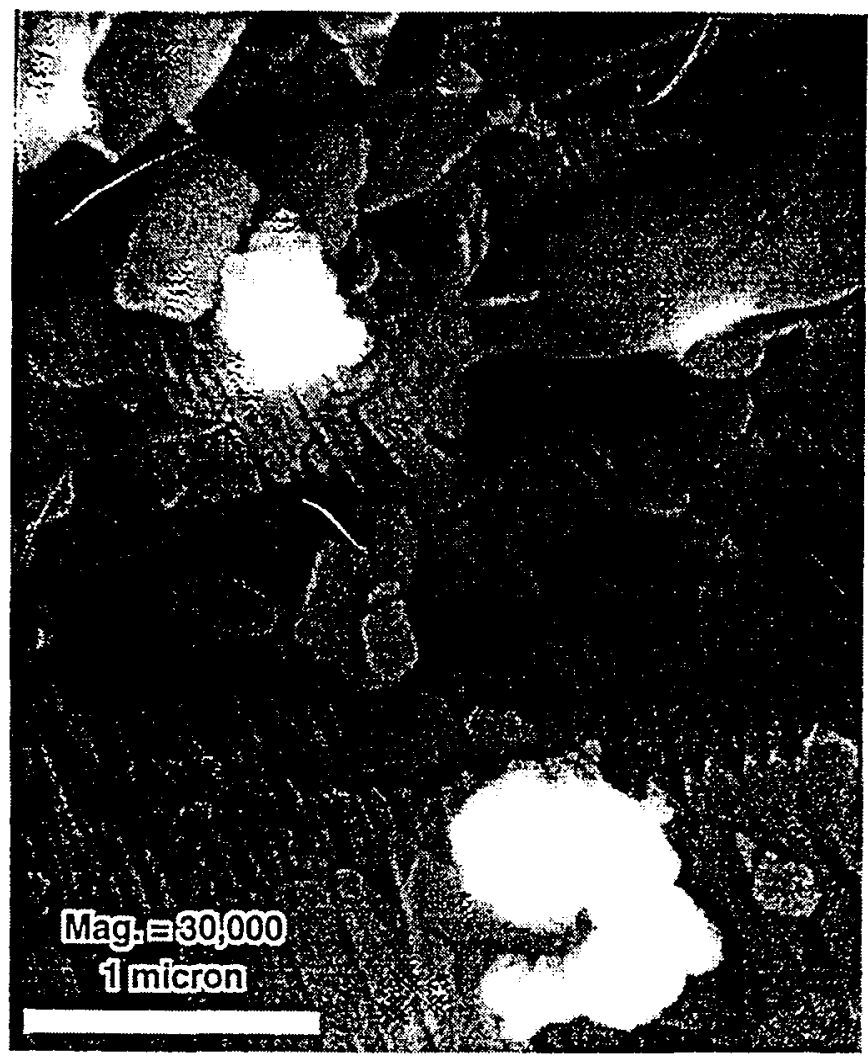


Modeling Changes in Mineral Assemblages and

Sorptive Capacity within the Altered Zone

Figure 18a. SEM photo of glass shards from the unreacted vitrophyre, PFR8-Z

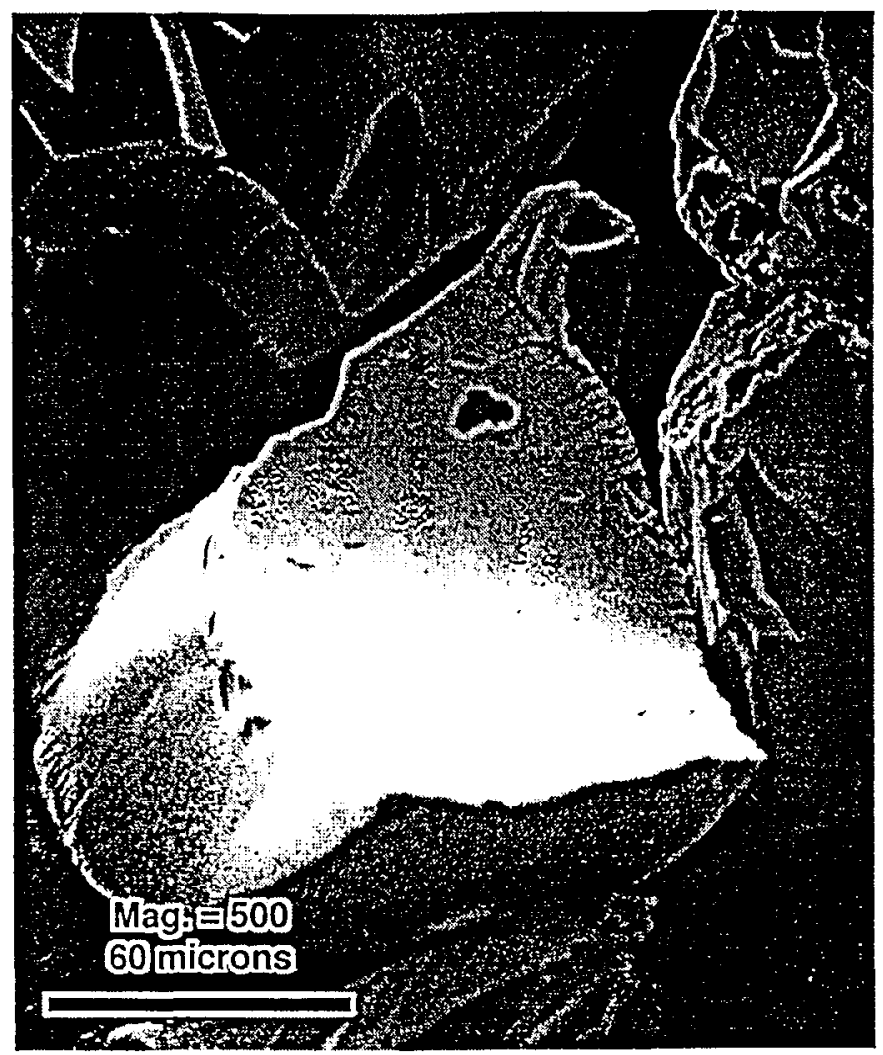

b. A representative $\mathrm{x}$-ray spectrum of a glass grain for qualitative chemistry (Pt - coating)

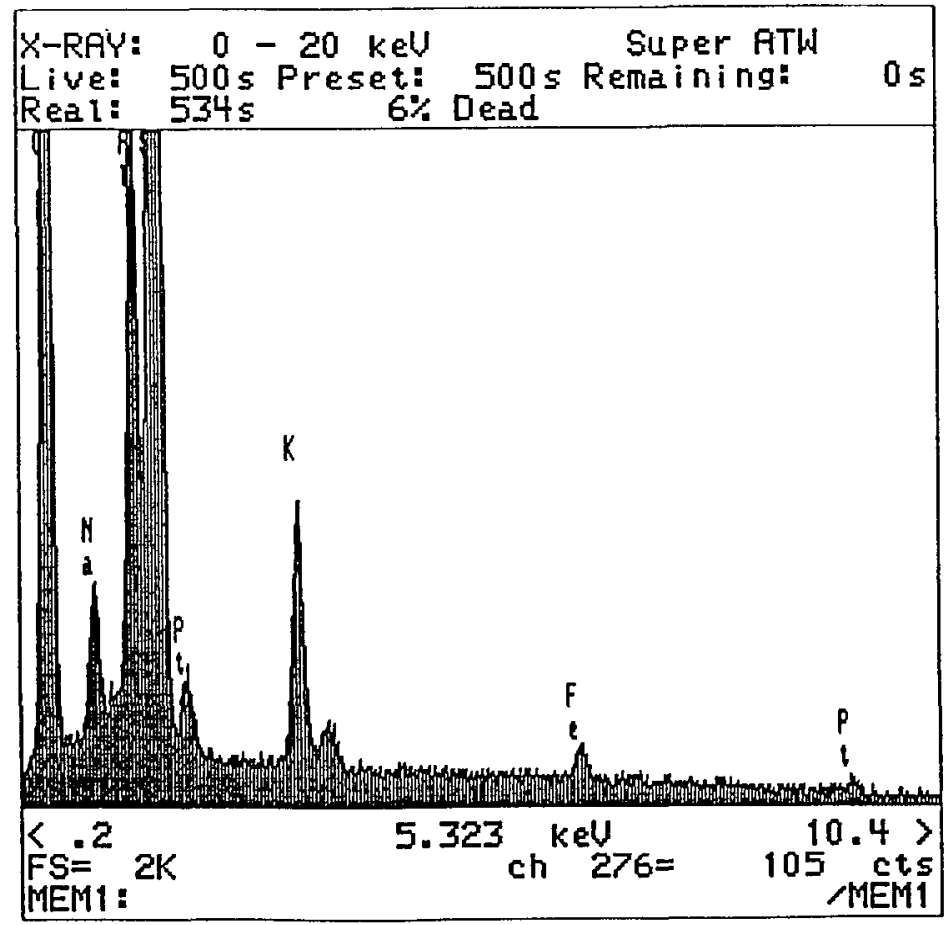


Figure 19. Glass dissolution and clay-altered regions observed among grains of the starting material, PFR8-Z

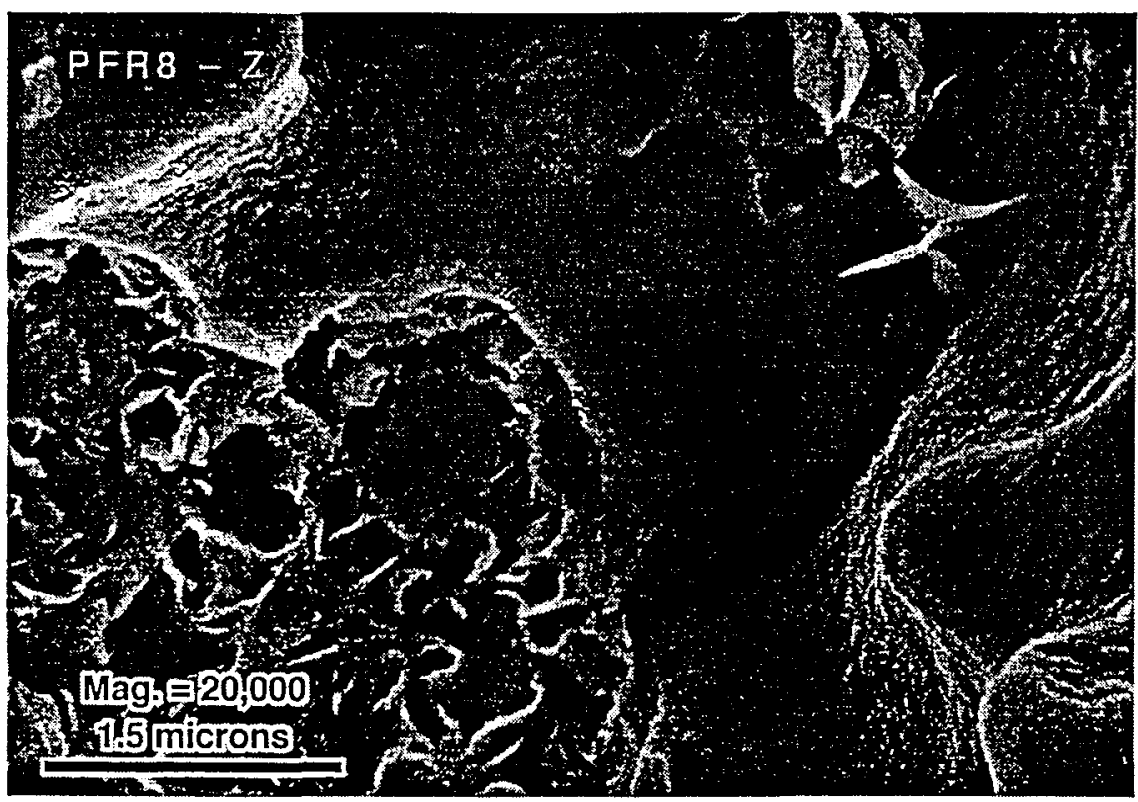


Figure 20. SEM photo revealing honeycomb growth pattern of clay phases and glass dissolution (sample from PFR8-A, but texture common to samples collected throughout plugflow reactor)

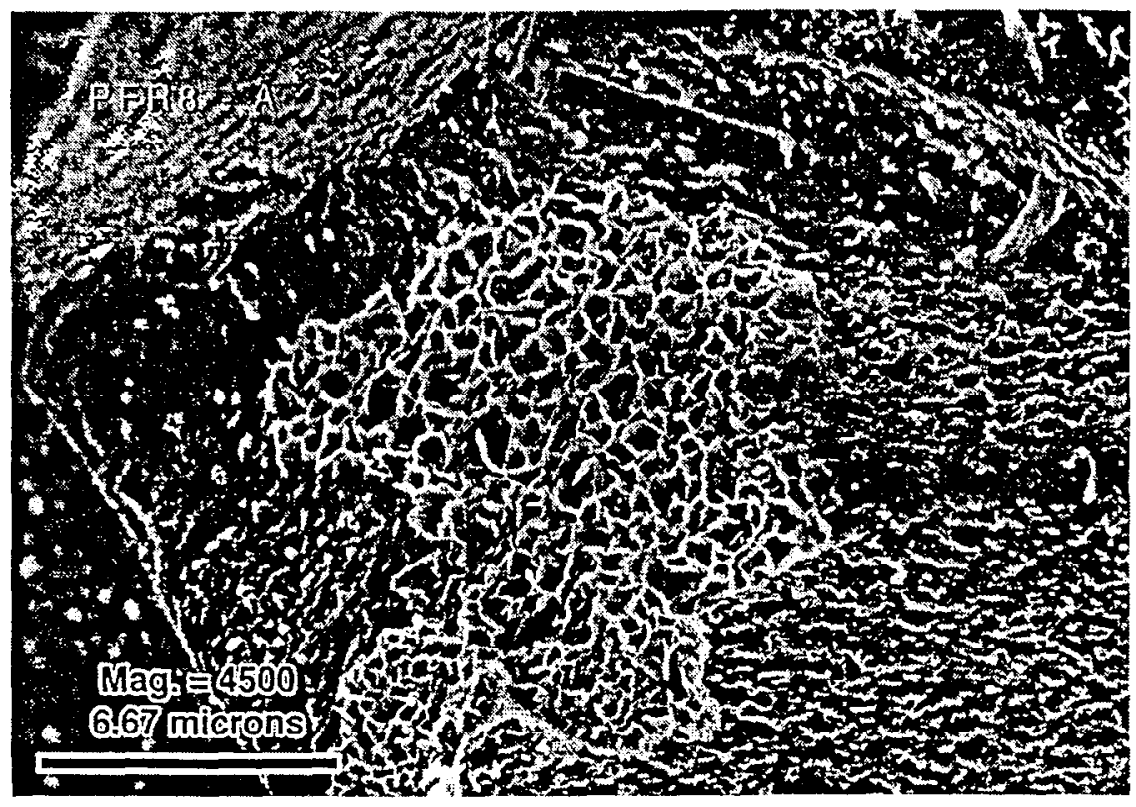


Modeling Changes in Mineral Assemblages and Sorptive Capacity within the Altered Zone

Figure 21a. SEM photo showing close-up of typical clay morphology (PFR8-UA)

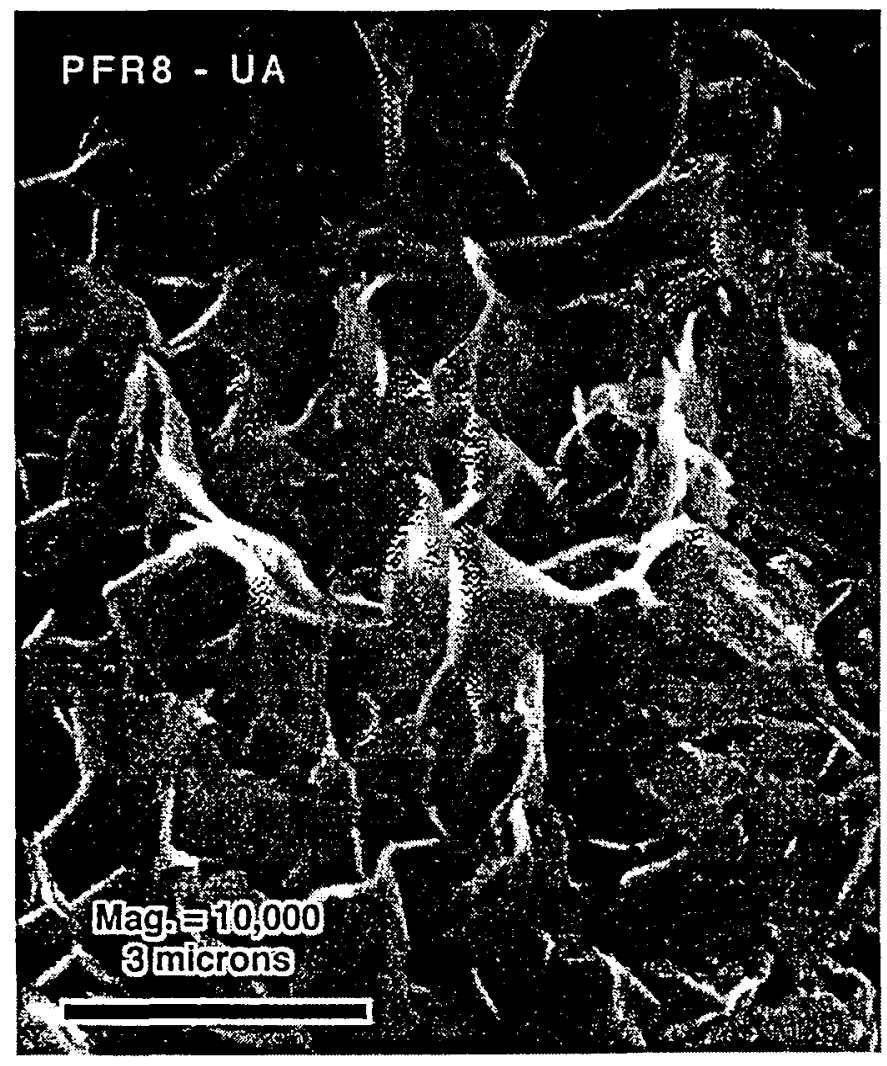

b. X-ray spectrum approximately corresponding to region shown in 21a; chemistry consistent with illite clay

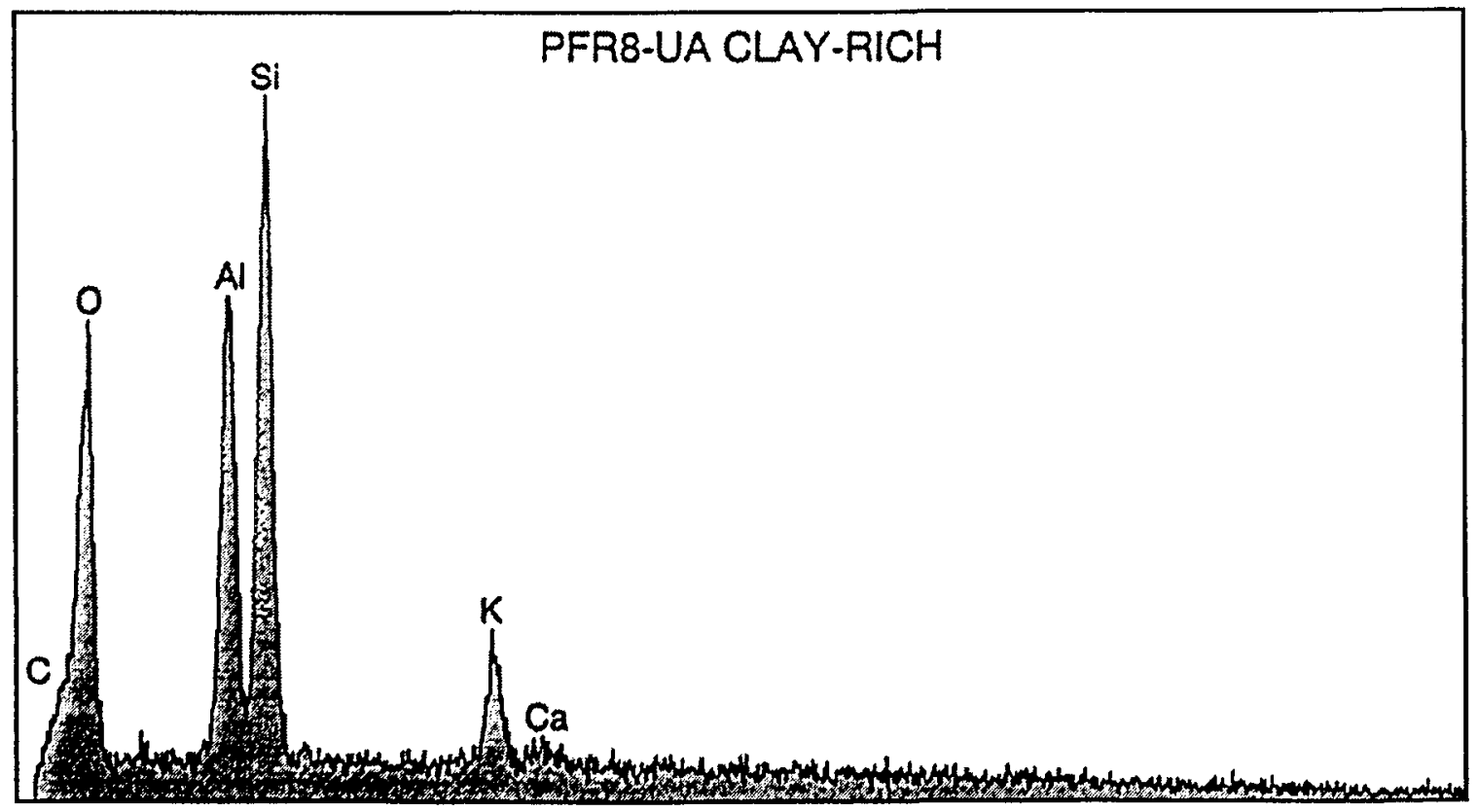


Figure 22. SEM photo of another clay morphology represented by ribbonlike texture

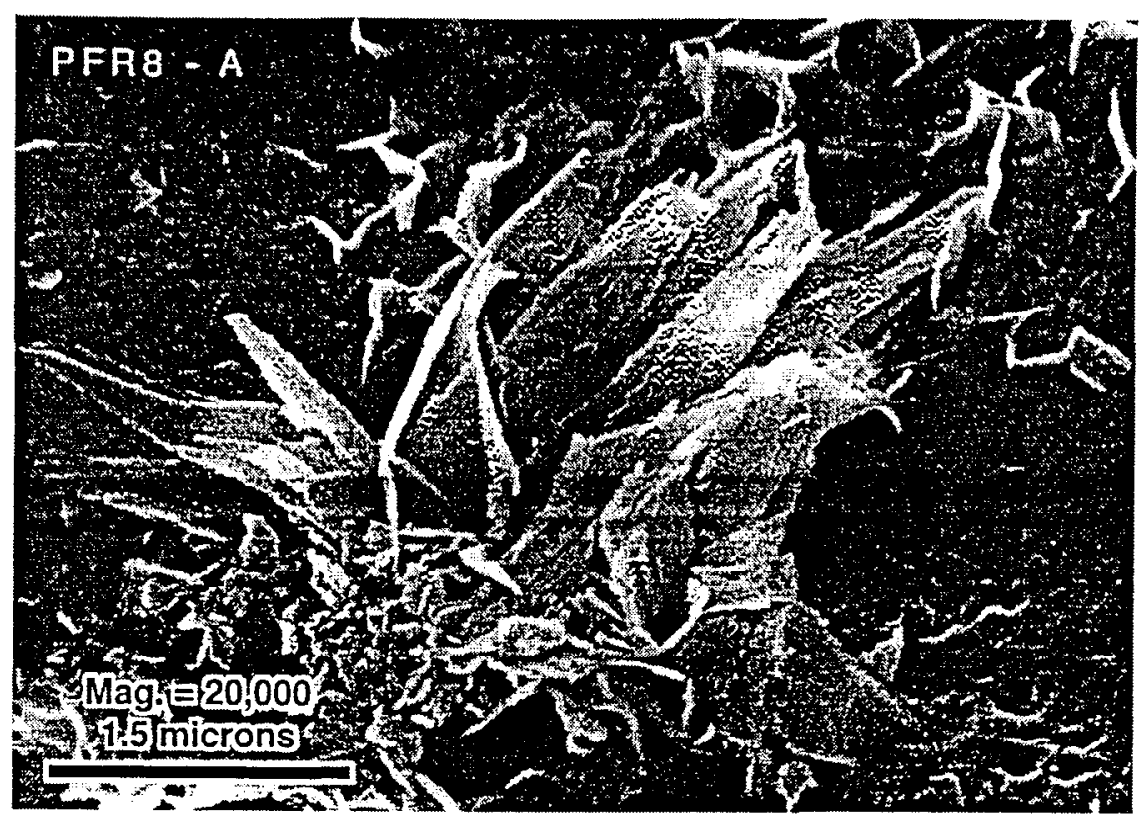


Modeling Changes in Mineral Assemblages and Sorptive Capacity within the Altered Zone

Figure 23. Sample PFR8-UA taken from walls of Ti-reaction vessel nearest the fluid inlet end and revealing dense presence of clays; (banding in photo is artifact of SEM instrument)

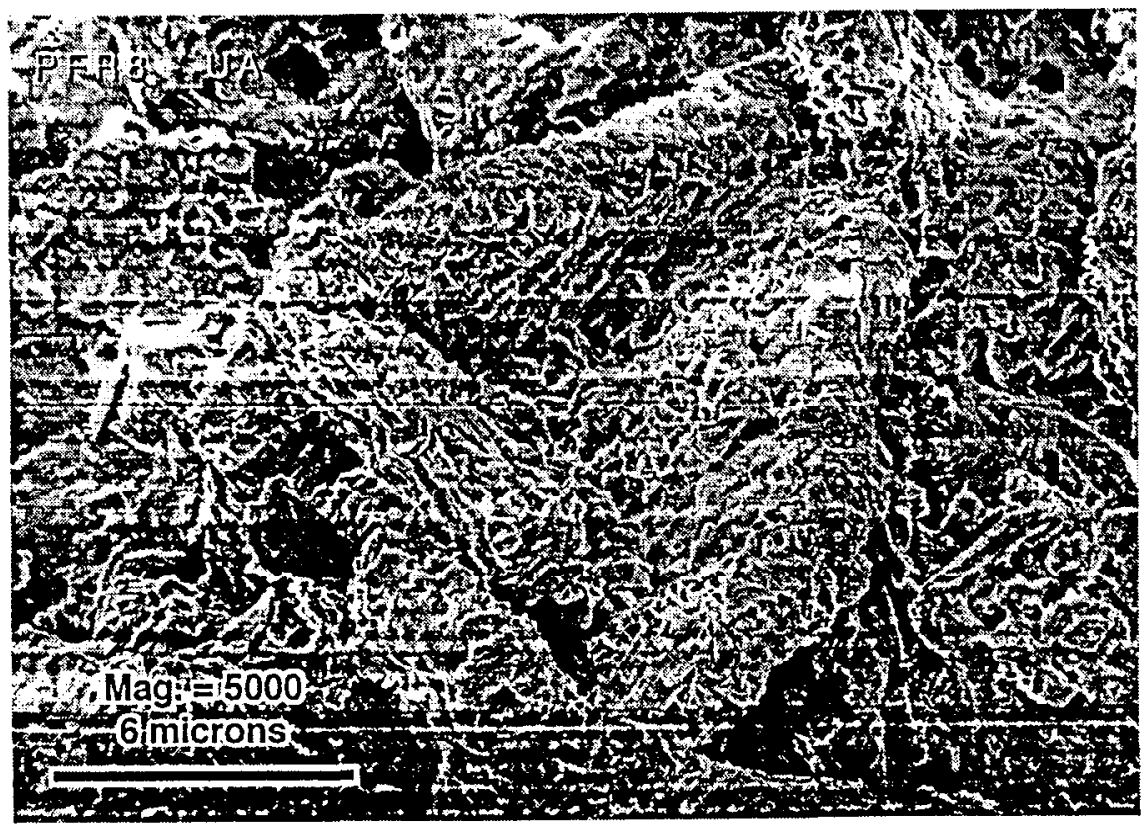


Figure 24a. The SEM photo shows blocky crystals observed among the clay-rich regions of sample PFR8-UA

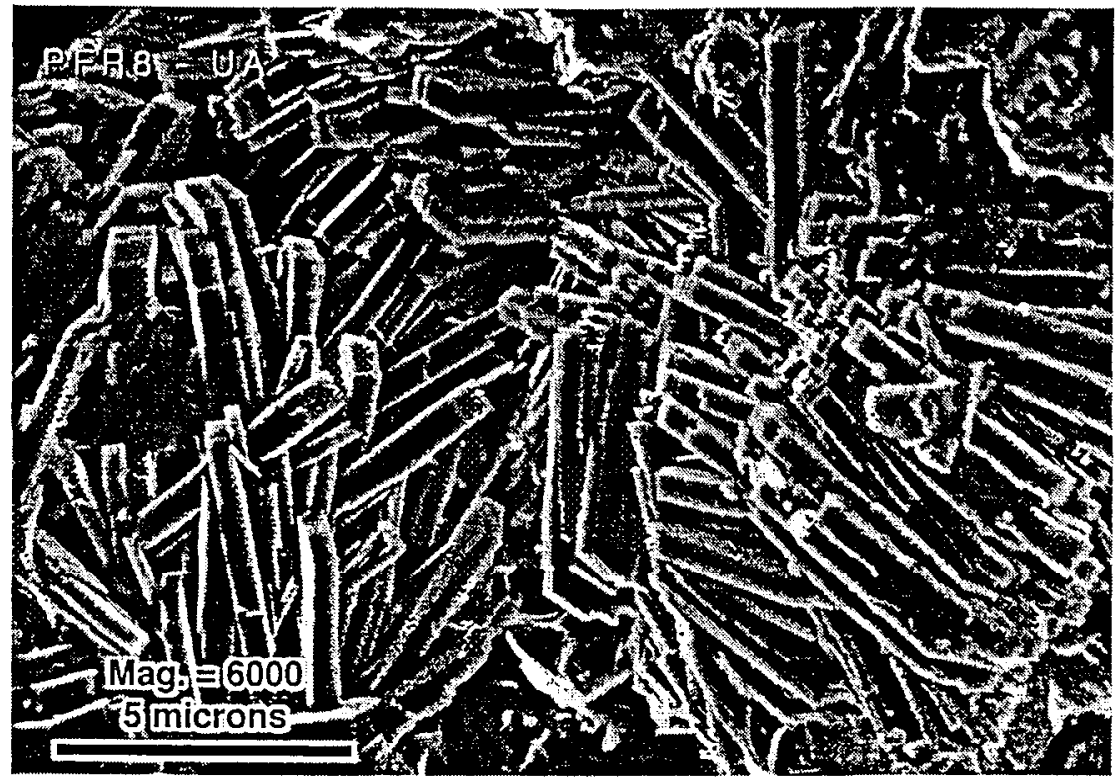

b. The X-ray spectrum corresponding to the region shown in 24a; chemistry consistent with a Ca-rich clinoptilolite

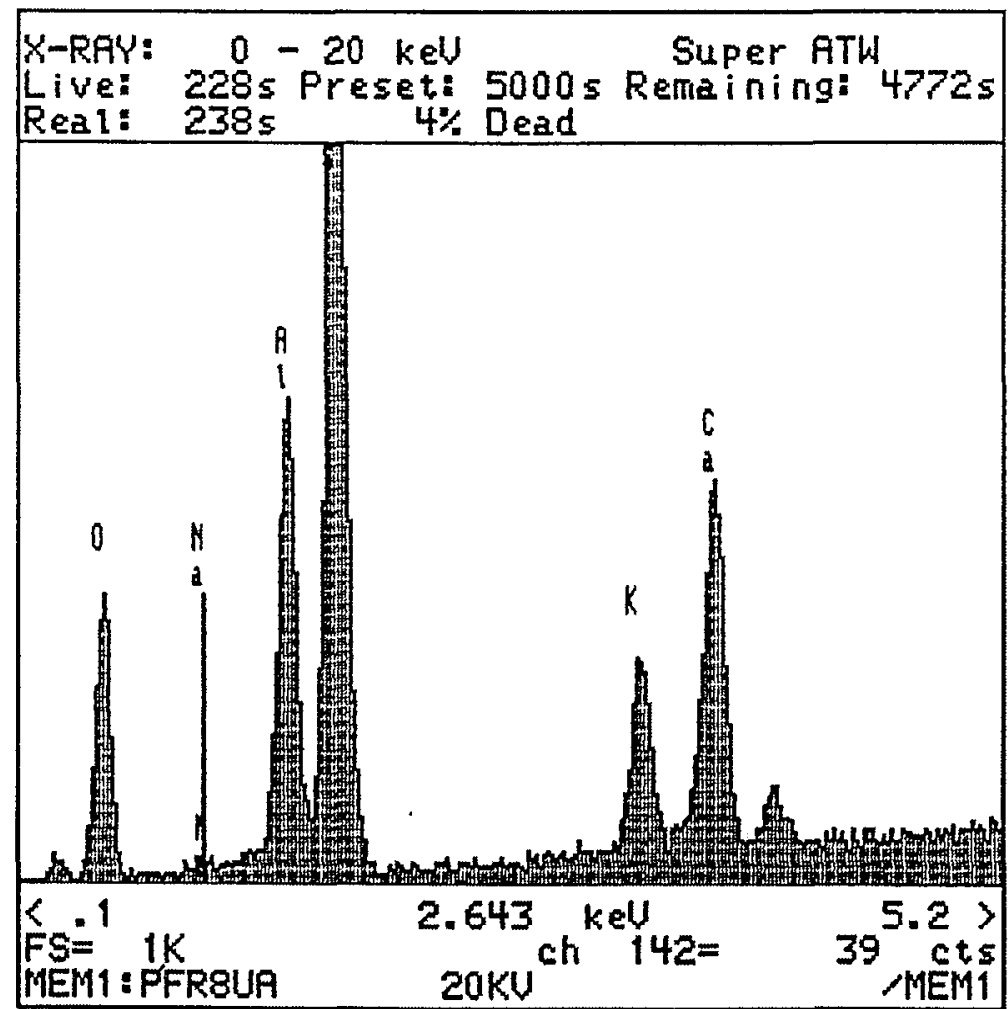




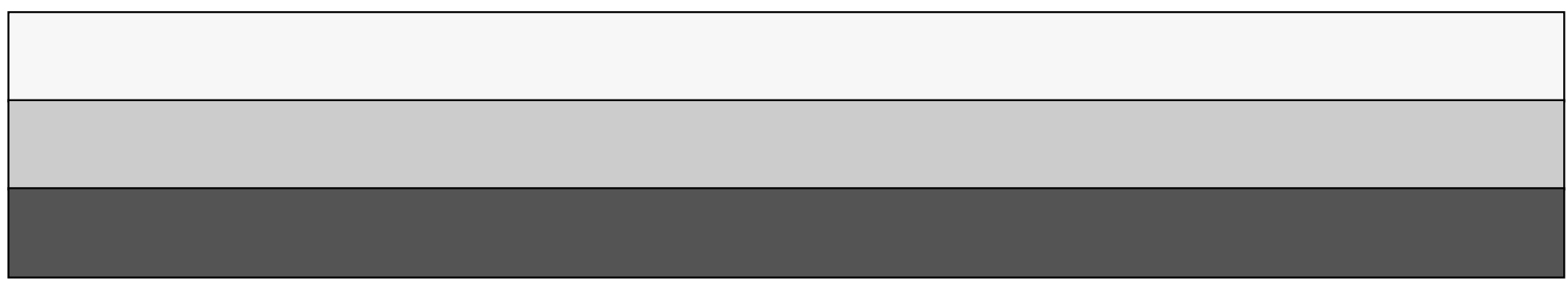

